\title{
Massive Vacancy Concentration Yields Strong Room-Temperature Ferromagnetism in
}

Two-Dimensional ZnO

Xin Yin $\ddagger$ Yizhan Wang $\ddagger$ Ryan Jacobs $\ddagger$, Yeqi Shi, Izabela Szlufarska, Dane Morgan, Xudong Wang*

Department of Materials Science and Engineering, University of Wisconsin-Madison, Madison, WI 53706, USA; ${ }^{\ddagger}$ These authors contributed equally: Xin Yin, Yizhan Wang, and Ryan Jacobs.

Email: xudong.wang@wisc.edu

\section{S1. Experimental section}

\section{S1.1. Synthesis at water-oil interface and water-air interface}

In a typical synthesis, the aqueous solution containing $25 \mathrm{mM}$ zinc nitrate $\left(\mathrm{Zn}\left(\mathrm{NO}_{3}\right)_{2}\right)$ and hexamethylenetetramine (HMT) was prepared in a $20 \mathrm{~mL}$ glass vial. $8 \mu \mathrm{L}$ chloroform solution of sodium oleyl sulfate $(\sim 0.1 \mathrm{vol} \%)$ was dispersed on the surface of the precursor solution. Twenty minutes was allowed for the evaporation of the chloroform and the formation of the surfactant monolayer at the water-air interface. Subsequently, $500 \mathrm{~mL}$ toluene (hexane or cyclohexane) was added to the top of the solution. The glass vial was then capped to form a closed reaction environment and placed in a $60^{\circ} \mathrm{C}$ convection oven for the growth of $\mathrm{ZnO}$ nanosheets. 1 hour and 45 minutes later, the growth was terminated by removing the glass vial from the oven and cooling down to room temperature naturally. The as-prepared $\mathrm{ZnO}$ nanosheets were transferred onto a $\mathrm{Si}$ substrate with thermal oxide by scooping at the surface of the reaction solution.

\section{S1.2. Characterization}

Zeiss LEO 1530 field-emission scanning electron microscope (SEM) was used to study the morphologies of the nanosheets. Atomic force microscopy (AFM) tomography images were obtained using an XE-70 Park System. X-ray photoelectron spectroscopy (XPS) spectrum was obtained from a Thermo Scientific K-alpha XPS instrument with a $100 \mu \mathrm{m}$ spot size, with the flood 
gun turned on during the measurements. FEI TF30 transmission electron microscope (TEM) operated at $300 \mathrm{kV}$ was used to study the crystal structure.

Focused ion beam (FIB, Zeiss Auriga) was used to prepare cross section scanning transmission electron microscopy (STEM) samples. The final FIB milling voltage of $5 \mathrm{kV}$ was used to minimize the damage from Ga ion beam. STEM images and EELS spectra were obtained on an FEI Titan with CEOS probe aberration corrector operated at $200 \mathrm{kV}$ with a probe convergence angle of 24.5 $\mathrm{mrad}$, spatial resolution of $0.08 \mathrm{~nm}$, and probe current of $\sim 70 \mathrm{pA}$ for STEM imaging and $\sim 150 \mathrm{pA}$ for electron energy loss spectroscopy (EELS). The elemental analysis was performed by using DigitalMicrograph EELS, one software provided by GATAN company. The mechanism about the analysis process is shown below:

The areal density of the element can be measured by taking the extracted edge count integral and dividing by the total number of counts in the spectrum, according to the equation below. ${ }^{1,2}$

$N=I_{k}(\beta, \Delta) / \sigma_{k}(\beta, \Delta) I_{l o w}(\beta, \Delta)$

Where $N$ is the projected areal density of the element, $I_{k}(\beta, \Delta)$ is the integral edge $k$ integrated over a specific energy width. $\beta$ is the effective collection angle, $\Delta$ is the signal integration width, $\sigma_{k}(\beta, \Delta)$ is the partial inelastic scattering cross-section, $I_{\text {low }}(\beta, \Delta)$ is the low-loss intensity integrated up to energy loss $\Delta$. The low-loss integral is used in place of the zero-loss integral to compensate for extra signals from plural scattering which is multiple scattering of one incident electron in the sample. It is realized through the deconvolution (Fourier-based methods) which is available in the DigitalMicrograph.

Based on equation 1, the atom ratio of two elements was calculated according to the equation below.

$$
N_{A} / N_{B}=\text { conc. } A / \text { conc. } B=I_{A}(\beta, \Delta) \sigma_{B}(\beta, \Delta) / I_{B}(\beta, \Delta) \sigma_{A}(\beta, \Delta)
$$

Where $I_{A}(\beta, \Delta)$ and $I_{B}(\beta, \Delta)$ were measured by the integration from the spectrum, and $\sigma_{A}(\beta, \Delta)$ and $\sigma_{B}(\beta, \Delta)$ were computed by utilizing some models, like Hartree Slater atomic wave functions, which is a built-in feature in the DigitalMicrograph.

The quantum Design MPMS3 magnetometer was used for the measurements of the magnetization as a function of applied magnetic field at both $5 \mathrm{~K}$ and $300 \mathrm{~K}$. The magnetic field was applied parallel to the nanosheets. The temperature-dependent magnetization was further probed by the zero field cooled (ZFC) and field cooled (FC) measurements, in which the samples were cooled to $5 \mathrm{~K}$ without and with a magnetic field of $500 \mathrm{Oe}$, respectively, and subsequently the magnetization was recorded when raising the temperature from $5 \mathrm{~K}$ to $300 \mathrm{~K}$ under the same magnetic field. 


\section{S2. Nanosheets grown at water-air interface}
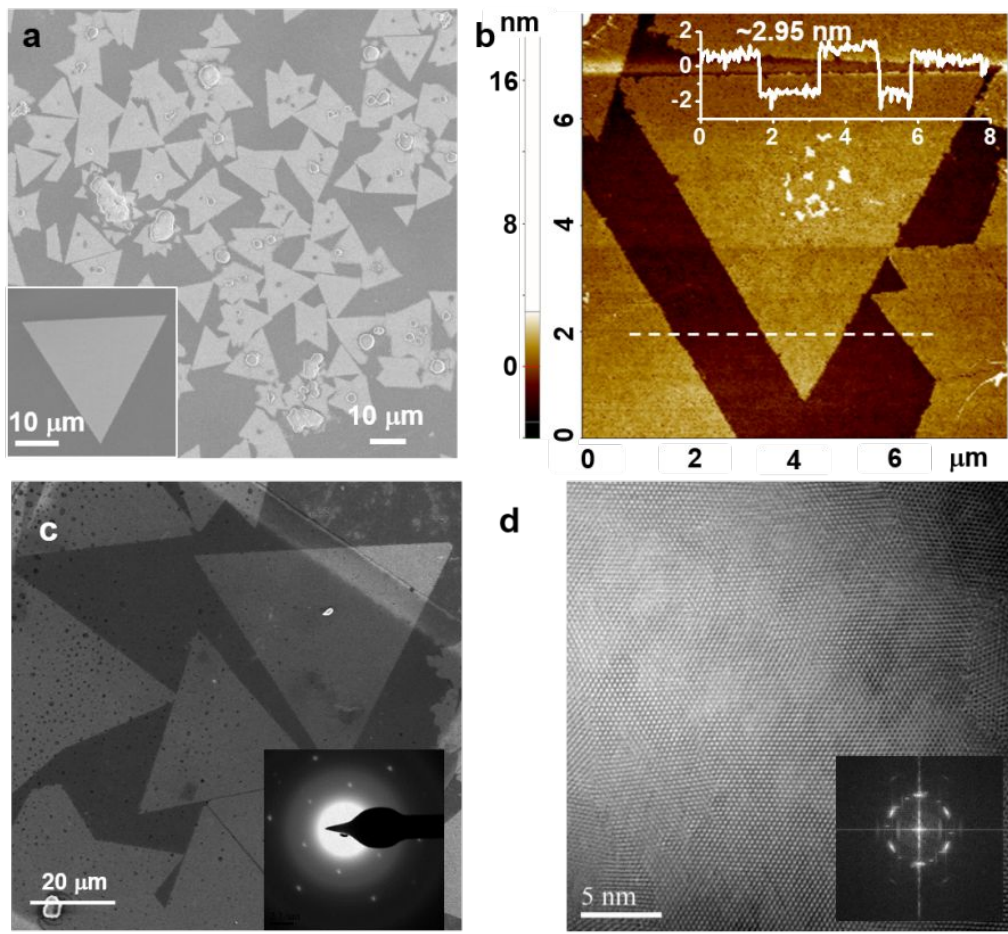

d

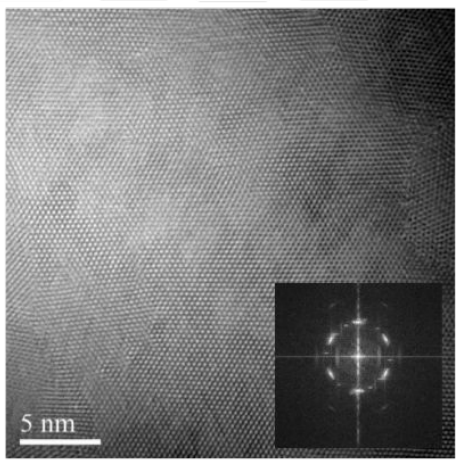

Fig. S1. (a) SEM image showing the densely distributed $\mathrm{ZnO}$ nanosheets grown at water-air interface. Inset is one individual nanosheet. (b) AFM topography image of the nanosheet. Inset is the height profile along the dashed line. (c) SEM image showing nanosheets rested on a holey carbon TEM grid. Inset is SAED pattern of the nanosheet. (d) High resolution TEM image showing the crystal lattice of wurtzite $\mathrm{ZnO}$. Inset is corresponding fast Fourier transform pattern of the nanosheet.

\section{S3. Molecular Dynamics Simulations}

Molecular dynamics (MD) simulations were performed using the GROMOS 54A7 force field, as implemented in the GROMACS 5.1.2 software package. This force field has been successfully used to model many surfactant systems. ${ }^{3-5}$ Force field parameters for sodium oleyl sulfate (SOS) molecules were taken from Sammalkorpi et al. ${ }^{6}$ and are the same as in our previous study. ${ }^{5}$ Interactions between ions of the same type were described using a combination of Lennard-Jones and Coulomb potentials with identical parameters as used by Sammalkorpi et al ${ }^{6}$ and Yin et al. ${ }^{5}$ Force field parameters for intra- and intermolecular interactions (e.g., interactions between $\mathrm{CH}_{3}$ groups on two different toluene molecules) were taken directly from Ref. ${ }^{7}$ and are listed in Table 
$\mathrm{S} 1$ and Table $\mathrm{S} 2$, respectively. In Table $\mathrm{S} 1$, the parameters $\mathrm{K}_{\mathrm{b}}, \mathrm{K}_{\theta}, \mathrm{K}_{\varphi}$ represent coefficients in different terms of the force field ${ }^{4}$. In particular, $K_{b}$ enters the covalent bond bending term $K_{b}\left[r^{2}-\right.$ $\left.r_{0}^{2}\right]^{2} / 4$, where $r_{0}$ is the equilibrium bond length. The molecular angle term is $K_{\theta}\left[\cos \theta-\cos \theta_{0}\right]^{2} / 2$, where $\theta_{0}$ is the equilibrium angle. $K_{\varphi}$ is the coefficient in the dihedral angle term $K_{\varphi}[1+$ $\left.\cos \left(\varphi_{0}\right) \cos (\mathrm{n} \varphi)\right]$, where $\varphi_{0}$ is the phase shift, which was restricted to 0 or $\pi$, and $n$ is the multiplicity of the torsional dihedral angle. Water was modeled using the SPC/E force field. ${ }^{8}$

All intermolecular interactions were calculated using a combination of the Lennard-Jones potential (with parameters $\varepsilon, \sigma$ ) and Coulomb (electrostatic) potential. For Lennard-Jones interactions between different groups and different ions, we calculated parameters based on the geometric rule of mixtures. Bond angles within the SOS molecules and toluene molecules were constrained using the LINCS algorithm and bond angles in water molecules were constrained using SETTLE. VMD 1.9.2 software was used for visualization.

Table S1. Intramolecular parameters for toluene. C stands for the carbon atom that is shared between $\mathrm{CH}_{3}$ group and toluene ring structure. $\mathrm{CR}_{1}$ represents carbon atoms in ring structure and $\mathrm{HC}$ means hydrogen atoms that are bonded to carbon atoms.

\begin{tabular}{|c|c|c|}
\hline Molecule covalent bonds & $\mathrm{K}_{\mathrm{b}}\left(\mathrm{kJ} \mathrm{mol}^{-1} \mathrm{~nm}^{-2}\right)$ & $\mathbf{r}_{0}(\mathrm{~nm})$ \\
\hline $\mathrm{CH}_{3}-\mathrm{C}$ & 334640 & 0.139 \\
\hline $\mathrm{C}-\mathrm{CR}_{1}$ & 417334 & 0.139 \\
\hline $\mathrm{CR}_{1}-\mathrm{HC}$ & 292273 & 0.109 \\
\hline $\mathrm{CR}_{1}-\mathrm{CR}_{1}$ & 417334 & 0.139 \\
\hline Molecule angles & $\mathrm{K}_{\theta}\left(\mathrm{kJ} \mathrm{mol}^{-1} \mathrm{rad}^{-2}\right)$ & $\Theta_{\mathrm{O}}(\mathrm{deg})$ \\
\hline $\mathrm{CH}_{3}-\mathrm{C}-\mathrm{CR}_{1}$ & 418.40 & 120.000 \\
\hline $\mathrm{CR}_{1}-\mathrm{C}-\mathrm{CR}_{1}$ & 418.40 & 120.000 \\
\hline $\mathrm{C}-\mathrm{CR}_{1}-\mathrm{CR}_{1}$ & 376.56 & 120.000 \\
\hline $\mathrm{CR}_{1}-\mathrm{CR}_{1}-\mathrm{CR}_{1}$ & 376.56 & 120.500 \\
\hline $\mathrm{C}-\mathrm{CR}_{1}-\mathrm{HC}$ & 376.56 & 120.000 \\
\hline $\mathrm{HC}-\mathrm{CR}_{1}-\mathrm{CR}_{1}$ & 376.56 & 120.500 \\
\hline
\end{tabular}




$\begin{array}{cccc}\mathrm{CH}_{3}-\mathrm{C}-\mathrm{CR}_{1}-\mathrm{CR}_{1} & 167.4 & 0.0 & 3 \\ \mathrm{CR}_{1}-\mathrm{C}-\mathrm{CR}_{1}-\mathrm{HC} & 167.4 & 0.0 & 3 \\ \mathrm{CR}_{1}-\mathrm{CR}_{1}-\mathrm{CR}_{1}-\mathrm{HC} & 167.4 & 0.0 & 3 \\ \mathrm{C}-\mathrm{CR}_{1}-\mathrm{CR}_{1}-\mathrm{CR}_{1} & 209.3 & 0.0 & 3 \\ \mathrm{CR}_{1}-\mathrm{CR}_{1}-\mathrm{CR}_{1}-\mathrm{CR}_{1} & 209.3 & 0.0 & 3 \\ \mathrm{CR}_{1}-\mathrm{C}-\mathrm{CR}_{1}-\mathrm{CR}_{1} & 209.3 & 0.0 & 3\end{array}$

Table S2. Intermolecular Force Field Parameters. C stands for the carbon atom that is shared between $\mathrm{CH}_{3}$ group and toluene ring structure. $\mathrm{CR}_{1}$ represents carbon atoms in ring structure and $\mathrm{HC}$ means hydrogen bonded to carbon atoms. Interactions between water molecules are modeled using SPC/E force field.

\begin{tabular}{|c|c|c|c|}
\hline atoms(or groups) & $\varepsilon\left(\mathrm{kJ} \mathrm{mol}^{-1}\right)$ & $\sigma(\AA)$ & $q(e V)$ \\
\hline $\mathrm{CH}_{3}$ & 0.8672 & 3.748 & +0.0400 \\
\hline C & 0.2014 & 3.564 & -0.0200 \\
\hline $\mathrm{CR}_{1}$ & 0.3288 & 3.496 & -0.1200 \\
\hline $\mathrm{HC}$ & 0.0000 & 0.000 & +0.0080 \\
\hline
\end{tabular}

The simulation system contained 8,575 water molecules. Equilibrated water (without ions, toluene or surfactants) at $300 \mathrm{~K}$ in a periodic system with dimensions $8 \mathrm{~nm} \times 8 \mathrm{~nm} \times 4 \mathrm{~nm}$ was provided by the GROMACS database; density of water is $1.002 \mathrm{~kg} / \mathrm{L}$. The equilibrated water was then placed into a larger box with dimensions of $8 \mathrm{~nm} \times 8 \mathrm{~nm} \times 30 \mathrm{~nm}$, and $26 \mathrm{~nm}$ of vacuum was created above the water surface. Periodic boundary conditions were applied in all spatial directions, and as a result the system had two vacuum-water interfaces. We placed SOS surfactants at one of these interfaces in such a way that the chain of the SOS molecules were in the vacuum layer and the head group was close to the water surface (initially the distance was less than $3.7 \AA$ ). The number of $\mathrm{Zn}^{2+}$ ions dissolved in water was consistent with the experimental $\mathrm{Zn}^{2+}$ concentration of $0.25 \mathrm{M} . \mathrm{Na}^{+}$and $\mathrm{Cl}^{-}$ions were also added to the system. Specifically, the number of $\mathrm{Na}^{+}$ions was the same as the number of surfactant molecules and the number of $\mathrm{Cl}^{-}$was chosen to balance the charge of the $\mathrm{Zn}^{2+}$ ions. Ions were added to the system by replacing random water molecules. In the next step, 864 vertically-oriented toluene molecules (a $4 \mathrm{~nm}$ thick layer) were placed between the SOS monolayer and the vacuum to form an oil (toluene)-surfactant (SOS)- 
water system. Static energy minimization with the steepest descent algorithm was used first to relax the simulation box which contains water, surfactants, toluene, and ions. Subsequently, each system was equilibrated for $2 \mathrm{~ns}$ at $300 \mathrm{~K}$ in a constant volume-constant temperature (NVT) ensemble. After equilibration, we performed production runs and the reported measurements correspond to averages taken over the last $30 \mathrm{~ns}$ of simulations in the NVT ensemble with a 2 fs timestep. A modified Berendsen thermostat was applied to control the temperature. Particle-Mesh Ewald was utilized to treat the long-range electrostatic interactions and the cut-off in the LennardJones interaction was $1 \mathrm{~nm}$. Different numbers of SOS molecules were added into the system to control the surface area of surfactants while keeping the simulation box a constant size.

\section{S4. Discussion about the kinetic control growth and ILE using other oil phases}

In material syntheses, kinetic control has been broadly implemented to stabilize nonequilibrium states and enable the creation of metastable structures with unprecedented properties. For example, metastable facets in $\mathrm{CdSe}$ and $\mathrm{TiO}_{2}$ were synthesized by modifying the chemical state of high-energy crystal surfaces with structural directing species, which brought higher photocatalytic performance..$^{9,10}$ Metastable Ga vacancies were introduced in GaN epilayers through a two-stage crystallization in chemical vapor epitaxy, enabling novel blue light emission. ${ }^{11}$ Metastable vacancies in carbon nanotubes were produced by controlling the formation of free radicals using low-energy argon ion treatments, offering a convenient pathway for surface functionalization. ${ }^{12} \mathrm{ZnO}$ nanoparticles with both zinc interstitials and oxygen vacancies were created far from equilibrium by greatly increasing the typical crystallization rate at a zinc-enriched condition, resulting in a significant enhancement of bandgap photoluminescence. ${ }^{13} 14$ lonic layer epitaxy (ILE) is a kinetically-controlled synthesis approach that uses an 
amphiphilic monolayer to direct the nucleation and crystal growth within a twodimensional (2D) space.

The organic solvents cyclohexane and hexane were also tested as the oil phases to synthesize $\mathrm{ZnO}$ nanosheets. The large-scale SEM image in Fig. S3a shows the dense ZnO nanosheets collected on a Si wafer when cyclohexane was used. The zoom-in SEM image on an individual nanosheet in Fig. S3b shows the side length of $\sim 10 \mu \mathrm{m}$, but with much rougher sides. There was observed overlayer growth on the nanosheets. The AFM topography image on such a representative nanosheet is shown in Fig. S3c. On the nanosheet, there is one smaller nanosheet at the center, as well as many tiny nanosheets randomly decorating the top of the nanosheet, indicating the overlayer growth. In addition, we observed these nanosheets grown with cyclohexane to have rough surfaces with many pinholes. All of these features indicate the poor crystal quality when using cyclohexane as the oil phase. The thickness for the basal nanosheet and the upper nanosheet were measured by AFM to be $4.2 \mathrm{~nm}$ and $4.3 \mathrm{~nm}$, respectively, indicating the accelerated out-ofplane growth. When hexane was used as the oil phase, the nanosheets in Fig. S4 show similar results, except the smaller nanosheet thickness of $\sim 2.3 \mathrm{~nm}$. The growth at water-cyclohexane, water-hexane, water-air, and water-toluene interfaces are summarized in Fig. S5. The thickness of the nanosheets was calculated based on measurements from more than 20 nanosheets. From the comparison, the thickness was the largest for cyclohexane $(\sim 4.4 \pm 0.4 \mathrm{~nm})$. When using hexane, the thickness decreased to $\sim 3.0 \pm 0.6 \mathrm{~nm}$, which is close to the nanosheet thickness at water-air interface $(\sim 2.8 \pm 0.3 \mathrm{~nm})$. Using toluene as the oil phase led to the smallest thickness $(\sim 1.8 \pm 0.1$ $\mathrm{nm})$. The different solubilities of sodium oleylsulfate in toluene, hexane and cyclohexane is responsible for the different growth results. The solubility of sodium oleylsulfate in hexane and cyclohexane was high, but it is negligible in toluene. Therefore, it is speculated that the large solubility could destroy the well-established surfactant monolayer and negatively impact the nanosheet growth. 

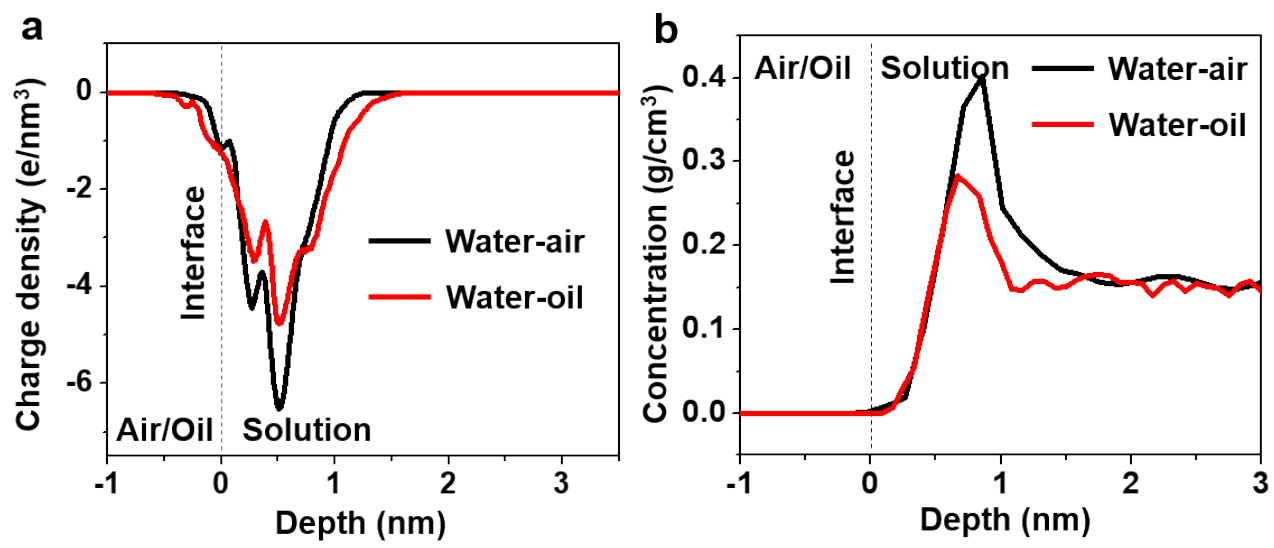

Fig. S2, a, Charge density along the depth direction into the aqueous solution. $\mathbf{b}, \mathrm{Zn}^{2+}$ ions concentration distribution along the depth direction into the aqueous solution. Based on the MD results, ionized surfactants at water-oil interface yielded $\sim 28 \%$ lower charge density compared to that at the water-air interface (Fig. 2a). As a result, the width of the Stern layer $\left(\mathrm{Zn}^{2+}\right.$-concentrated zone) at the water-oil interface was $\sim 45 \%$ narrower than that at the water-air interface (Fig. 2b). Therefore, thinner nanosheets with a narrower thickness distribution were obtained from the water-oil interface. 

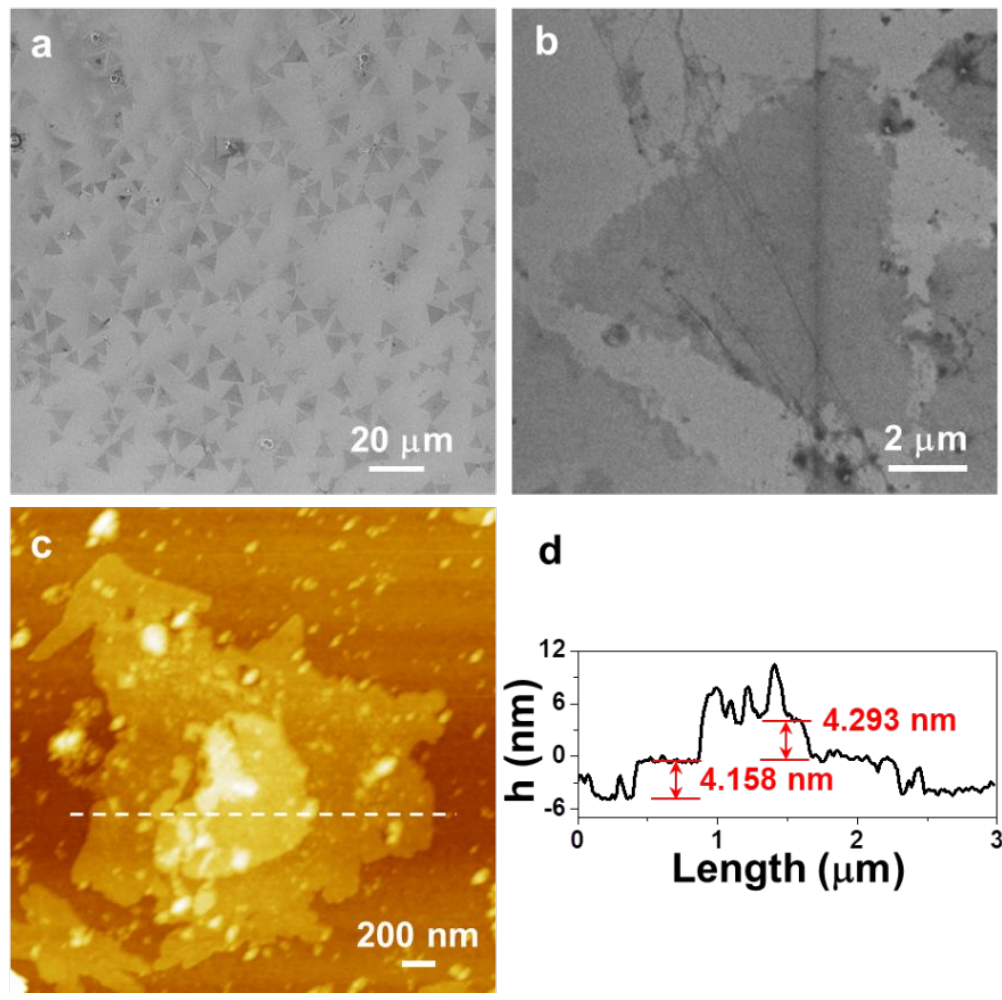

\section{d}

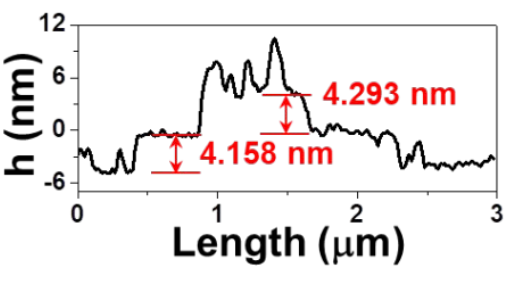

Fig. S3. ZnO nanosheets grown at water-cyclohexane interface. (a) Large scale SEM image showing the nanosheets on the Si substrate. (b) Enlarged SEM image showing one individual nanosheet. (c) AFM topography image. (d) Height profile of the nanosheet along the dashed line in (c). 

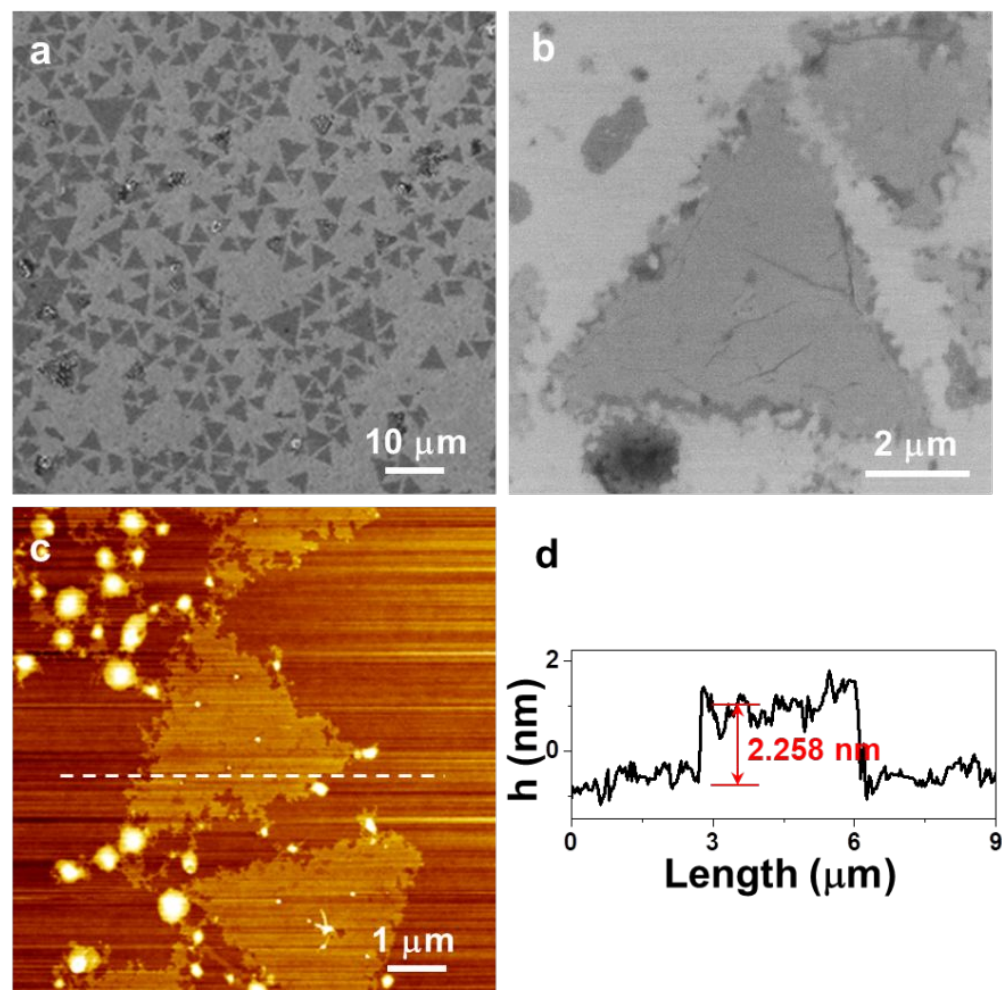

d

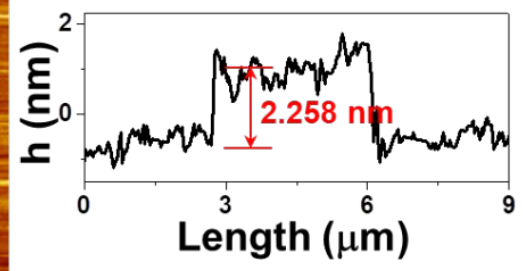

Fig. S4. ZnO nanosheets grown at water-hexane interface. (a) Large scale SEM image showing the nanosheets on the Si substrate. (b) Enlarged SEM image showing one individual nanosheet. (c) AFM topography image. (d) Height profile of the nanosheet along the dashed line in (c). 


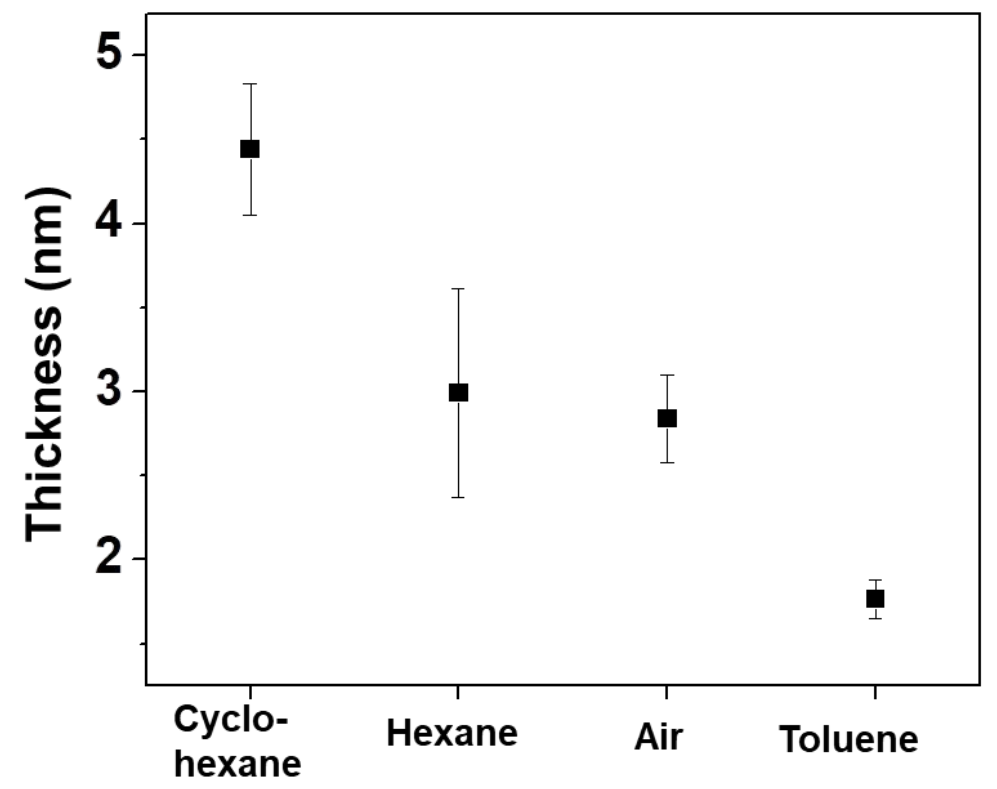

Fig S5. Thickness comparison of the nanosheets grown at water-cyclohexane, water-hexane, water-air, and water-toluene interfaces. The error bars represent calculated standard deviations in nanosheet thickness taken over 20 AFM thickness measurements. 
S5. Magnetic properties of the nanosheets before annealing.
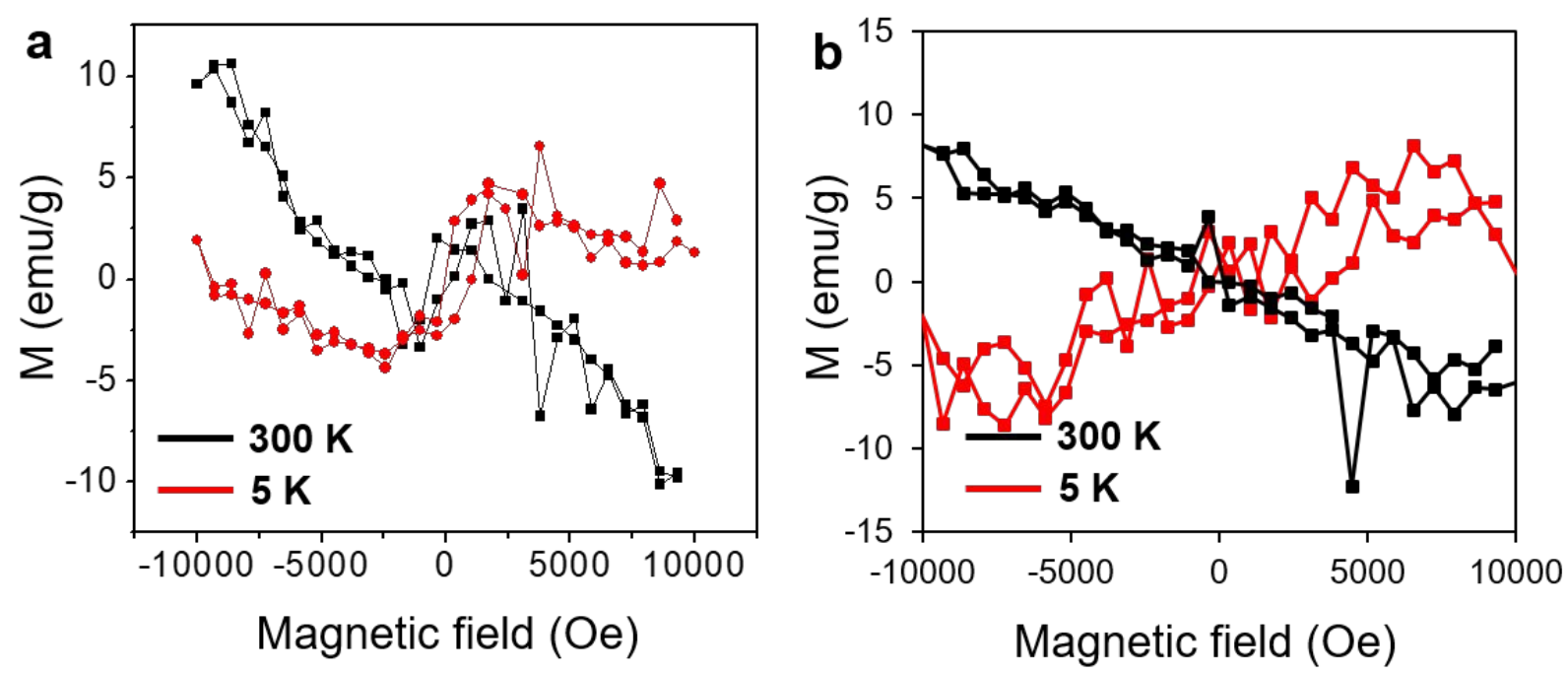

Fig. S6 Magnetic properties of the nanosheets grown at (a) water-air interface and (b) wateroil interface before annealing. 
S6. The structure and magnetic properties of $\mathrm{ZnO}$ nanosheets after annealing
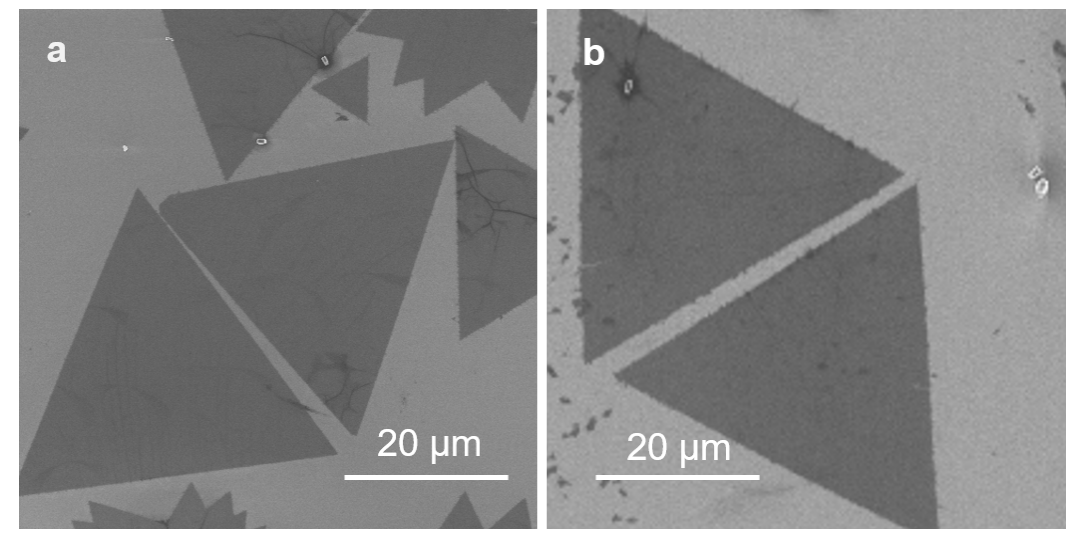

Fig. S7. The morphology of $\mathrm{ZnO}$ nanosheets after annealing in (a) Ar and (b) then in $\mathbf{H}_{2}$.

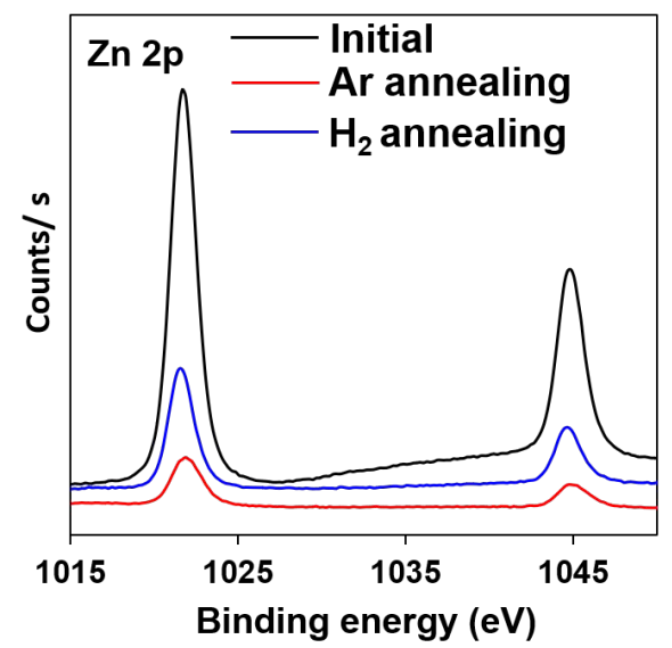

Fig. S8. XPS spectra of $\mathrm{ZnO}$ nanosheets before and after annealing. 

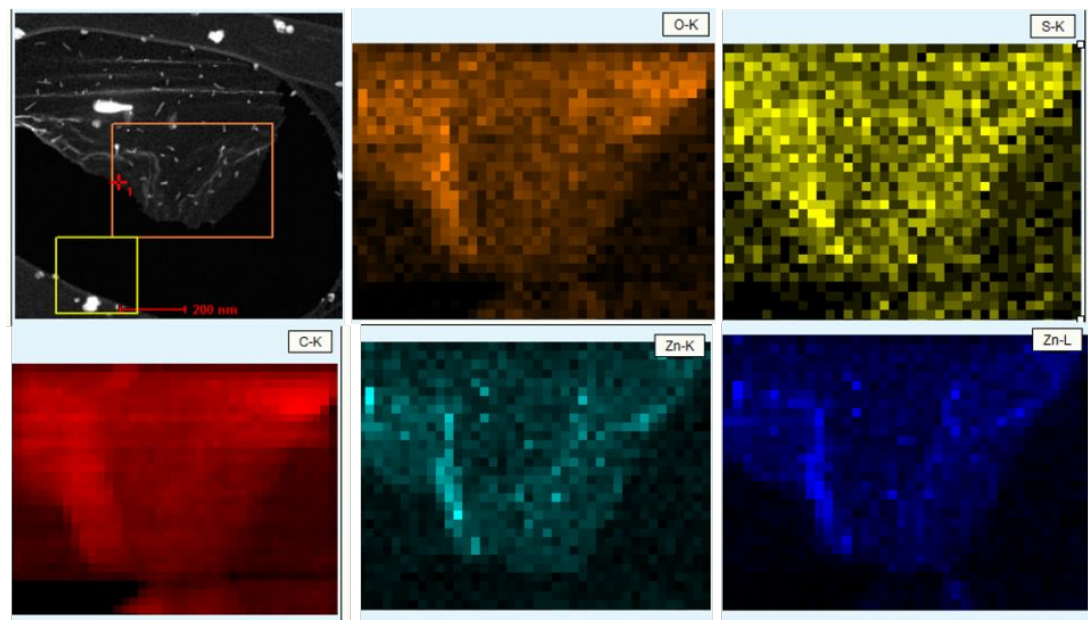

Fig. S9. EDS mapping of ZnO nanosheets after Ar annealing
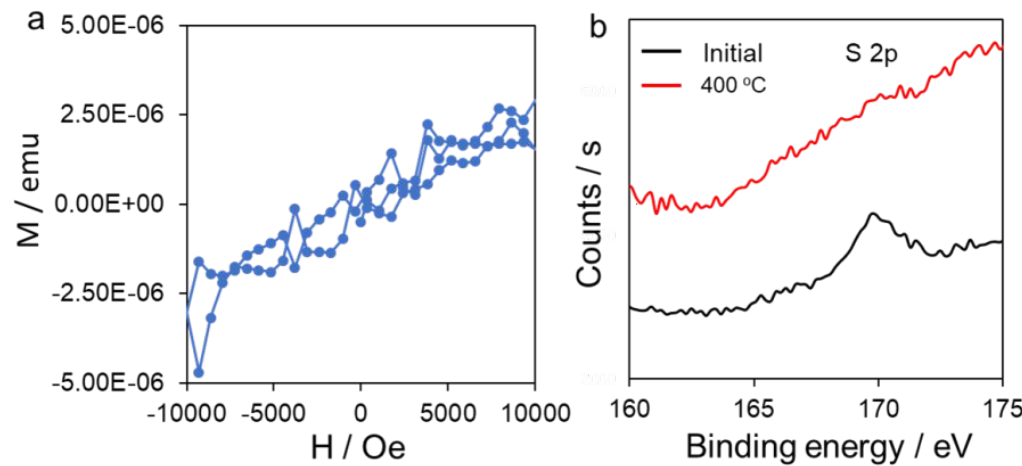

Fig. S10. a) Magnetic properties of $\mathrm{ZnO}$ nanosheet after annealing in $\mathrm{O}_{2}$ at $400^{\circ} \mathrm{C}$ for $1 \mathrm{~h}$. b) XPS spectra of $\mathrm{ZnO}$ nanosheets after annealing in $\mathbf{O}_{2}$. After annealing as-prepared $\mathrm{ZnO}$ nanosheets in $\mathrm{O}_{2}$ at $400{ }^{\circ} \mathrm{C}$ for one hour, the sample doesn't have the ferromagnetic property, as shown in following Fig. S10a. We further checked the XPS of the annealed sample. The sulfur element from surfactants could not be observed (Fig. S10b), which indicated that the surfactant residue on $\mathrm{ZnO}$ nanosheet surface was removed after annealing in $\mathrm{O}_{2}$. Annealing in $\mathrm{O}_{2}$ can destroy the $\mathrm{Zn}$ vacancies on $\mathrm{ZnO}$ and resulted in the absence of ferromagnetic properties

\section{S7. Cross-section TEM image of the $\mathrm{ZnO}$ nanosheet}




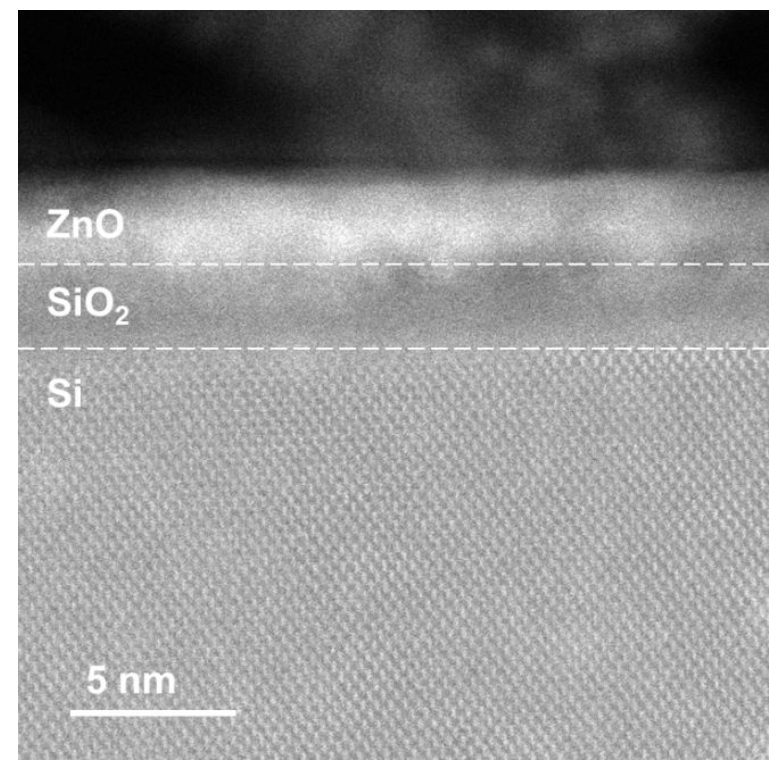

Fig. S11. Cross-section TEM image of the nanosheets on the $\mathrm{SiO}_{2} / \mathrm{Si}$ substrate. The thickness of the thermal oxide layer $\left(\mathrm{SiO}_{2}\right)$ is $\sim 3 \mathrm{~nm}$. 


\section{S8. Density Functional Theory Simulations.}

All Density Functional Theory (DFT) calculations were performed using the Vienna Ab Initio Simulation Package (VASP) ${ }^{15}$ with a planewave basis set, projector augmented wave (PAW) ${ }^{16}$ Perdew-Burke-Ernzerhof (PBE)-type pseudopotentials, ${ }^{17}$ and the hybrid functional of Heyd, Scuseria and Ernzerhof (HSE) ${ }^{18}$ with a Hartree-Fock exchange fraction of 0.375 , following previous DFT-HSE studies of $\mathrm{ZnO} .{ }^{19-22}$ The use of 0.375 as the Hartree-Fock exchange fraction results in a bandgap of $3.45 \mathrm{eV}$, in excellent agreement both with experiment and previous DFTHSE studies of $\mathrm{ZnO} .{ }^{20,21,23}$ All calculations were performed with spin polarization enabled and a planewave cutoff energy of $500 \mathrm{eV}$. Undefected bulk wurtzite $\mathrm{ZnO}$ (spacegroup $\mathrm{P}_{3} m c$ ) was simulated using a $3 \times 3 \times 4$ supercell (144 atoms) of the primitive cell and a $1 \times 1 \times 1 k$-point mesh. The dilute $\mathrm{Zn}$ vacancy $\left(\mathrm{V}_{\mathrm{Zn}}\right)$ and $33 \% \mathrm{~V}_{\mathrm{Zn}}$ ordering in the "criss-cross" arrangement were made with this $3 \times 3 \times 4$ supercell (144 atoms) supercell. In order to have the correct ordering periodicity along the $z$-direction, a smaller $3 \times 3 \times 3$ supercell (108 atoms) was used for the $33 \% \mathrm{~V}_{\mathrm{Zn}}$ "layered", "staggered" and "screw" arrangements (see Fig. S12 for structure models). The dilute $\mathrm{V}_{\mathrm{Zn}}$ simulations were performed at fixed volume and only allowing ions to relax, consistent with their representing formation energies of highly dilute species. The $33 \% \mathrm{~V}_{\mathrm{Zn}}$ simulations were performed with full volume and ion relaxation, owing to the possibility that these highly defected $\mathrm{ZnO}$ structures may have relaxed lattice parameters that differ markedly from the bulk stoichiometric $\mathrm{ZnO}$ structure. (0001)-oriented $\mathrm{ZnO}$ surfaces were constructed using the $3 \times 3 \times 4$ bulk cell and adding a >10 A vacuum region normal to the (0001) terminating surface, and were simulated using a $1 \times 1 \times 1 \quad k$-point mesh. The O-terminated (0001) surface was reconstructed using the stable $\mathrm{V}_{\mathrm{Zn}}(1 / 3)-10 / 9 \mathrm{H}_{\mathrm{ads}}$ surface structure found in the work of Jacobs et al. ${ }^{24}$ and the Zn-terminated (0001) surface was reconstructed using the stable $\mathrm{OH}_{\mathrm{ads}}(4 / 9)$ surface following the work of Dulub et al. ${ }^{25}$ and Kresse et al. ${ }^{26}$ Both of these surfaces are expected to be stable for the $T=298 \mathrm{~K}$ and $p\left(\mathrm{O}_{2}\right)=0.2 \mathrm{~atm}$ conditions used in this study. As with the bulk simulations, for dilute $\mathrm{V}_{\mathrm{Zn}}$ in the surface slab only ions were allowed to relax while the lattice parameters and overall volume were kept fixed, while for the highly defected $33 \% \mathrm{~V}_{\mathrm{Zn}}$ structure the volume and ions were both allowed to relax (note that due to the vacuum layer height this has negligible impact on the energy as this is equivalent to relaxing ions and area in the plane of the slab). For the calculation of dilute $\mathrm{V}_{\mathrm{Zn}}$ in the surface slab, the $\mathrm{V}_{\mathrm{Zn}}$ in the slab was positioned in the layer beneath the $\mathrm{Zn}$-terminated surface. 
For the case of $33 \% \mathrm{~V}_{\mathrm{Zn}}$ in the surface slab, only the "criss-cross" ordering was simulated. The following six grain boundary structures from the works of Körner et al. ${ }^{27-29}$ denoted (from the

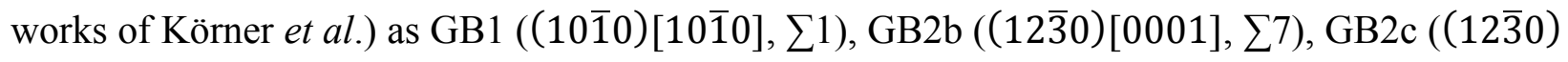

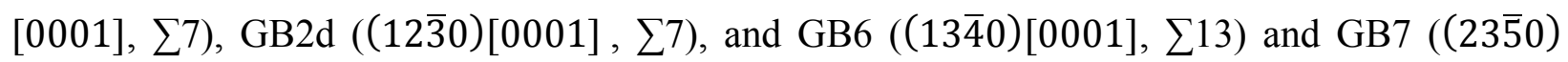
[0001], $\left.\sum 19\right)$ were simulated. The structures were taken from the works of Körner et al. ${ }^{27-29}$. Files with coordinates for all structures used in this work are shared as part of the digital supporting information.

In this work, we have calculated unpassivated and $\mathrm{H}$-passivated $\mathrm{V}_{\mathrm{Zn}}$ defects in bulk, surface slab and grain boundary structures of $\mathrm{ZnO}$. All of these calculations were done as neutral defects at the HSE level. Calculating all defects as neutral is appropriate based on the findings of Frodason et $a l$., who found that the stable defect is either neutral $\mathrm{V}_{\mathrm{Zn}}+2 \mathrm{H}$ (H present) or neutral $\mathrm{V}_{\mathrm{Zn}}$ (no $\mathrm{H}$ present), as discussed in Section S10. The defect formation energy calculations were performed by following previous studies, ${ }^{20-22,30,31}$ where here we have studied dilute $\mathrm{V}_{\mathrm{Zn}}$ defects by removing a single $\mathrm{Zn}$ atom from the bulk, surface, or grain boundary supercell under study, and $\mathrm{H}$ were added to passivate the $\mathrm{Zn}$ vacancies in a manner following previous DFT studies, which sought to minimize $\mathrm{H}$ interaction and multiple $\mathrm{H}$ bonding to a single $\mathrm{O} .{ }^{32-34} \mathrm{In}$ addition to dilute $\mathrm{Zn}$ vacancies, we have simulated structures with a high concentration of $33 \% \mathrm{Zn}$ vacancies. For bulk $\mathrm{ZnO}$, four different orderings of highly defective $\mathrm{ZnO}$ containing $33 \% \mathrm{Zn}$ vacancies were simulated, while for the surface slab of $\mathrm{ZnO}$ only a single $33 \% \mathrm{Zn}$ vacancy ordering was simulated. The four bulk $33 \%$ Zn vacancy orderings are referred to as "layered", "staggered", "screw", and "criss-cross" structures. Atomic structural models used to simulate these different $\mathrm{Zn}$ vacancy orderings is shown in Fig. S12. These orderings were constructed based on the studies of Ye et al. ("screw"), ${ }^{18}$ Peng et al. ("layered", "screw"), ${ }^{19}$ Ho and Chen ("staggered") ${ }^{20}$ and the "criss-cross" structure was developed in this work based on the surface vacancy structure found in Jacobs et al. ${ }^{10} \mathrm{We}$ note here that while such a high concentration of $33 \% \mathrm{Zn}$ vacancies, has, to our knowledge, not previously been reported to occur in $\mathrm{ZnO}$ prior to this study, the studies referenced above for the various $33 \%$ vacancy ordering structures were found to occur in the chalcogenide materials $\left(\mathrm{Ga}_{\mathrm{x}} \mathrm{In}_{1-\mathrm{x}}\right)_{2} \mathrm{Se}_{3}$ (Ye et al.), ${ }^{18}\left(\mathrm{In}_{\mathrm{x}} \mathrm{Ga}_{1-\mathrm{x}}\right)_{2} \mathrm{Se}_{3}$ (Peng et al.), ${ }^{19}$ and $\mathrm{Ga}_{2} \mathrm{~S}_{3}$ (Ho and Chen) ${ }^{20}$ which were referred to as having a "defected wurtzite" structure where one-third of the $\mathrm{Ga} / \mathrm{In}$ cation sites were vacant. A $33 \% \mathrm{Zn}$ vacancy structure in $\mathrm{ZnO}$ was reported for a single surface in 
the work of Jacobs et al. ${ }^{24}$ and Yankovich et al. ${ }^{35}$, but these studies did not suggest that a bulk 33\% Zn vacancy structure existed.

In this study, we considered the reference states of $\mathrm{O}, \mathrm{H}$, and $\mathrm{Zn}$ to be $\mathrm{O}_{2}$ gas, liquid $\mathrm{H}_{2} \mathrm{O}$, and bulk wurtzite $\mathrm{ZnO}$, respectively. The general thermodynamic formalism and derivation of the chemical potentials follows the work of Nørskov et al. ${ }^{21}$ and Man et al. ${ }^{22}$ Additional details about the defect formation energy calculations and chemical potentials can be found in Section S9.

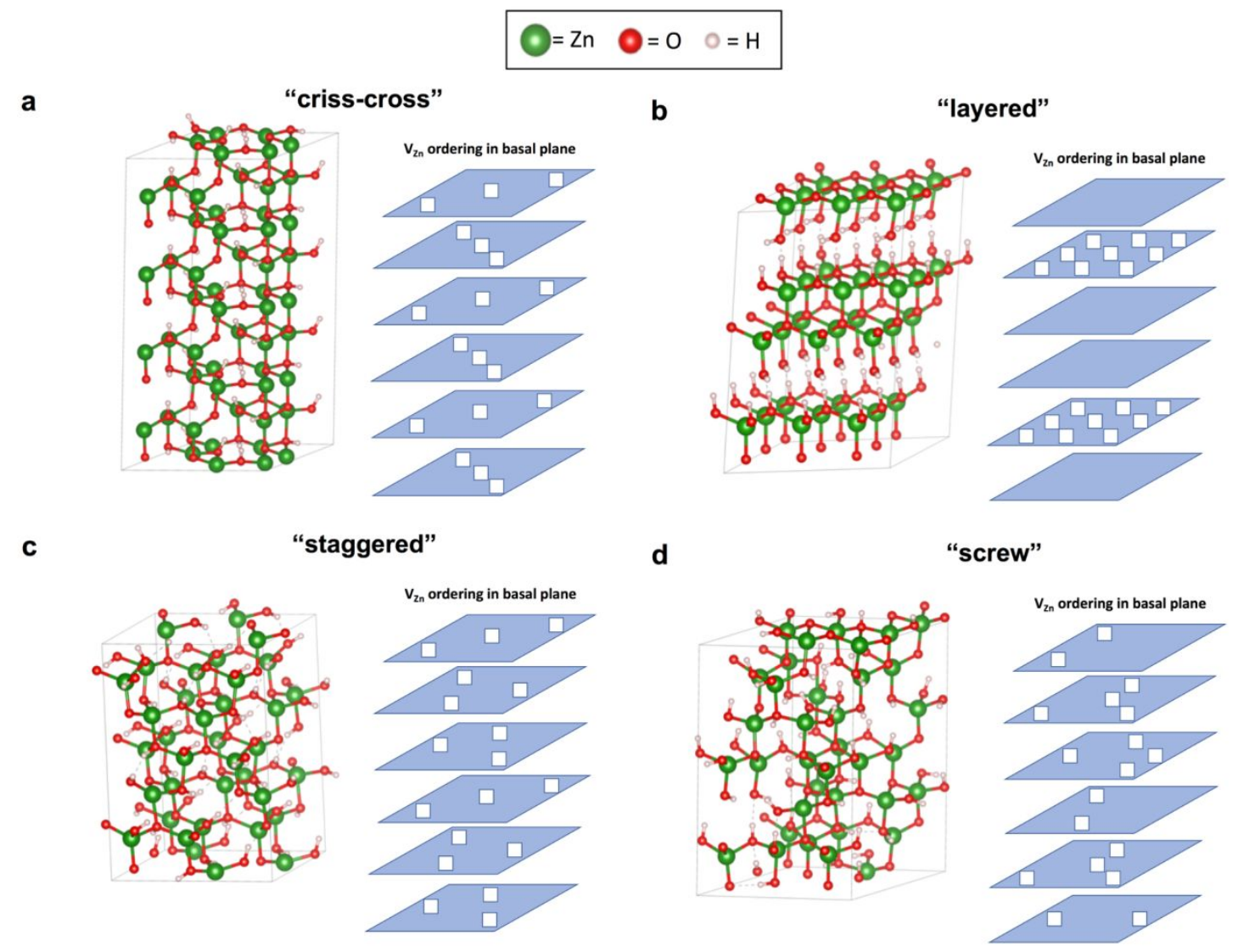

Fig S12. Structural models of $33 \% \mathrm{Zn}$ vacancy orderings simulated in this work. (a) "crisscross" model (new for this work, based on Jacobs et al. ${ }^{10}$ ), (b) "layered" model based on Peng et al. ${ }^{19}$ (c) "staggered" model based on Ho and Chen, ${ }^{20}$ (d) "screw" model based on Ye et al. ${ }^{18}$ and Peng et al. ${ }^{19}$ 


\section{S9. Defect calculations and thermodynamic formalism}

In this work, DFT was used to calculate defect formation energies of $\mathrm{Zn}$ vacancies $\left(\mathrm{V}_{\mathrm{Zn}}\right)$ in $\mathrm{ZnO}$. Our approach for calculating defect formation energies followed the well-known Zhang-Northrup formalism, ${ }^{23}$ which has been successful in formulating defect models for a range of materials systems, including $\mathrm{ZnO} .{ }^{19-22,}$ 30, 31, 36-39 The defect formation energy $\Delta E_{\text {form }}$ takes the form:

$$
\Delta E_{\text {form }}=E_{Z n O}^{\text {defected }}-E_{Z n O}^{\text {perfect }}-\sum_{i} \Delta n_{i} \mu_{i}-\Delta n_{e} \mu_{e}
$$

where $E_{Z n O}^{\text {defected }}$ is the DFT-calculated energy of the defected ZnO supercell, $E_{Z n O}^{\text {perfect }}$ is the DFTcalculated energy of the perfect (undefected) $\mathrm{ZnO}$ supercell, $\Delta n_{i}\left(\mu_{i}\right)$ is the number of atoms (chemical potential) of atom type $i$ involved in the creation of the defect, $\Delta n_{e}$ is the number of electrons involved in the creation of the defect, and $\mu_{e}$ is the electron chemical potential. In this work, we report the defect formation energies of defects in neutral charge states only $\left(\Delta n_{e}=0\right)$. The physical reasoning behind this choice is discussed in Section S10 in the context of previously published work of bulk $\mathrm{ZnO}$ defect energetics from Frodason et al. ${ }^{6,7}$

In this study, $\mathrm{ZnO}$ was grown in both water and oil. Therefore, for all defect calculations, we took the reference states of $\mathrm{O}, \mathrm{H}$, and $\mathrm{Zn}$ to be $\mathrm{O}_{2}$ gas, liquid $\mathrm{H}_{2} \mathrm{O}$, and bulk wurtzite $\mathrm{ZnO}$ (this is sometimes called O-rich conditions), respectively, where we have assumed the that $\mathrm{H}$ chemical potential in the oil is approximately equal to that in the water. The thermodynamic growth conditions of $\mathrm{ZnO}$ correspond to $T=298 \mathrm{~K}$ and $p\left(\mathrm{O}_{2}\right)=0.2 \mathrm{~atm}$. The $\mathrm{O}$ chemical potential $\mu_{O}(T, P)$ can be written as:

$$
\mu_{O}(T, P)=\frac{1}{2} \mathrm{E}_{O_{2}}(D F T)+\Delta \mu_{O}(T, P)
$$

where $\mathrm{E}_{\mathrm{O}_{2}}(D F T)$ is the DFT-calculated energy of an isolated $\mathrm{O}_{2}$ molecule and $\Delta \mu_{O}(T, P)$ represents the energy shift of $\mathrm{E}_{O_{2}}(D F T)$ to produce a value of $\mu_{O}(T, P)$ in accordance with $T=298$ $\mathrm{K}$ and $p\left(\mathrm{O}_{2}\right)=0.2 \mathrm{~atm}$. The value of $\Delta \mu_{O}(T, P)$ was calculated using the zero-point energy and entropy contributions as described in the work of Nørskov et al. ${ }^{40}$ and Man et al., ${ }^{41}$ along with the 
ideal gas partial pressure correction and the vibrational entropy correction using an Einstein model and assuming an Einstein temperature of $500 \mathrm{~K}$ following the previous study of Jacobs et al. (see Table S3) ${ }^{26}$ As the growth of $\mathrm{ZnO}$ was conducted in water under these $T$ and $p\left(\mathrm{O}_{2}\right)$ conditions, $\mathrm{H}_{2}$ is in equilibrium with $\mathrm{O}_{2}$ and liquid $\mathrm{H}_{2} \mathrm{O}$ at $T=298 \mathrm{~K}$. The $\mathrm{H}$ chemical potential $\mu_{H}(T, P)$ can thus be expressed as:

$$
\mu_{H}(T, P)=\frac{1}{2}\left(E_{H_{2} O}(D F T)+\Delta \mu_{H_{2} O}(T, P)-\mu_{O}(T, P)\right)
$$

where $E_{\mathrm{H}_{2} \mathrm{O}}(D F T)$ is the DFT-calculated energy of an isolated $\mathrm{H}_{2} \mathrm{O}$ molecule, $\Delta \mu_{\mathrm{H}_{2} \mathrm{O}}(T, P)$ is the energy shift of $E_{\mathrm{H}_{2} \mathrm{O}}(D F T)$ to produce a value of $\mu_{\mathrm{H}_{2} \mathrm{O}}(T, P)$ in accordance with $T=298 \mathrm{~K}$ and $p\left(\mathrm{H}_{2} \mathrm{O}\right)=0.0313 \mathrm{~atm}$ (the vapor pressure of $\mathrm{H}_{2} \mathrm{O}$ at $298 \mathrm{~K}$ ). The value of $\Delta \mu_{H_{2} O}(T, P)$ was calculated using the zero-point energy and entropy contributions as described in the work of Nørskov et al. ${ }^{40}$ and Man et al. ${ }^{41}$ (see Table S3). Finally, as the reference state of $\mathrm{Zn}$ is bulk $\mathrm{ZnO}$, the $\mathrm{Zn}$ chemical potential $\mu_{Z n}(T, P)$ is:

$$
\mu_{Z n}(T, P)=E_{Z n o}(D F T)-\mu_{O}(T, P)
$$

where $E_{Z n O}(D F T)$ is the DFT-calculated energy of bulk ZnO. A summary of the chemical potentials used in this work is provided in Table S3.

Table S3. Chemical potentials used in defect thermodynamic analysis. Summary of calculated DFT energies of reference states, reference state energy shifts to coincide with $(T, P)$ conditions of this study, and resultant chemical potentials used in the defect calculations in this work.

\begin{tabular}{|c|c|c|c|}
\hline Species $\boldsymbol{i}$ & $\mathbf{E}_{\boldsymbol{i}}(\boldsymbol{D} \boldsymbol{F T})(\mathbf{e V} / \mathbf{s p e c i e s} \boldsymbol{i})$ & $\Delta \boldsymbol{\mu}_{\boldsymbol{i}}(\boldsymbol{T}, \boldsymbol{P})(\mathbf{e V} / \mathbf{s p e c i e s} \boldsymbol{i})$ & $\left.\boldsymbol{\mu}_{\boldsymbol{i}}(\boldsymbol{T}, \boldsymbol{P})(\mathrm{eV} / \mathbf{s p e c i e s} \boldsymbol{i})\right)$ \\
\hline $\mathrm{O}$ & -7.792 & -0.268 & -8.059 \\
\hline $\mathrm{H}_{2} \mathrm{O}$ & -19.108 & -0.199 & -19.307 \\
\hline $\mathrm{H}$ & --- & --- & -5.624 \\
\hline $\mathrm{ZnO}$ & -12.666 & --- & --- \\
\hline $\mathrm{Zn}$ & --- & --- & -4.607 \\
\hline
\end{tabular}




\section{S10. Findings of bulk $\mathrm{ZnO}$ defect model from previous work}

To understand the expected stable charge state of $\mathrm{Zn}$ vacancies $\left(\mathrm{V}_{\mathrm{Zn}}\right)$ in $\mathrm{ZnO}$ and to compare our calculated formation energies of dilute defects in $\mathrm{ZnO}$, we used results from the previous work of Frodason et al., who calculated the bulk $\mathrm{ZnO}$ defect energetics at the HSE level. ${ }^{20,21}$ The work of Frodason et al. constructed a full defect model of defect formation energy as a function of Fermi level under so-called "O-rich" conditions (reference states of $\mathrm{O}, \mathrm{Zn}$ and $\mathrm{H}$ were $\mathrm{O}_{2}$ gas, $\mathrm{ZnO}$ and $\mathrm{H}_{2} \mathrm{O}$, the same as this work but without the $\Delta \mu_{i}(T, P)$ shifts applied to the chemical potential of each species), which incorporated both neutral and several positive and negative charge states for the following defect types: $\mathrm{V}_{\mathrm{Zn}}, \mathrm{V}_{\mathrm{Zn}}+1 \mathrm{H}, \mathrm{V}_{\mathrm{Zn}}+2 \mathrm{H}$, and $\mathrm{V}_{\mathrm{Zn}}+3 \mathrm{H}$. In the plot of defect formation energy as a function of Fermi level, charge neutrality will cause the Fermi level to be pinned at or near the crossing of the positively and negatively charged defects, which in the work of Frodason et al. occurs near $2.4 \mathrm{eV}$ above the valence band maximum (note the bandgap of $\mathrm{ZnO}$ is $3.4 \mathrm{eV}$ ). At this pinned crossing point of about $2.4 \mathrm{eV}$ above the valence band maximum, the most stable defect is the neutral $\mathrm{V}_{\mathrm{Zn}}+2 \mathrm{H}$ defect. When $\mathrm{H}$ is not present in the system (e.g. when annealing in $\mathrm{Ar}$ ), the charge neutrality point occurs in the range of approximately $0.75-1.4 \mathrm{eV}$ above the valence band maximum, and neutral unpassivated $\mathrm{V}_{\mathrm{Zn}}$ is the stable defect. Therefore, when $\mathrm{H}$ is removed from the system, the equilibrium Fermi level shifts toward the valence band maximum and the material becomes more p-type. This trend makes sense as there is no $\mathrm{H}$ to passivate the $\mathrm{V}_{\mathrm{Zn}}$ defects, and the unpassivated $\mathrm{V}_{\mathrm{Zn}}$ will each nominally dope two holes into the system. The finding in Frodason et al. that the neutral $\mathrm{V}_{\mathrm{Zn}}+2 \mathrm{H}\left(\mathrm{V}_{\mathrm{Zn}}\right)$ defect is the stable defect in the presence of $\mathrm{H}$ (no $\mathrm{H}$ ) in bulk $\mathrm{ZnO}$ justifies our investigation of neutral $\mathrm{H}$-passivated $\mathrm{V}_{\mathrm{Zn}}$ (unpassivated $\mathrm{V}_{\mathrm{Zn}}$ ) in $\mathrm{ZnO}$ bulk, surfaces and grain boundaries as discussed in Section S11 (bulk) and Section S12 (surfaces and grain boundaries).

We remark here that the defects with the lowest formation energy in Frodason et al. ${ }^{20}$, 21 (i.e. those that are most likely to form during the synthesis of $\mathrm{ZnO}$ nanosheets in this work) are all either passivated with $\mathrm{H}$ or charge compensated such that they have no magnetic moment and are thus magnetically inactive defects (moments calculated via bulk HSE calculations, see Table S4 for results of magnetic moments). Therefore, it is likely that knowing the precise nature of $\mathrm{H}$ passivation of $\mathrm{V}_{\mathrm{Zn}}$ (i.e. whether $\mathrm{V}_{\mathrm{Zn}}$ is passivated with 1, 2 or $3 \mathrm{H}$ atoms) does not affect any of 
the main conclusions of this work, as the purpose of the $\mathrm{H}$ is to donate electrons to stabilize the presence of $\mathrm{V}_{\mathrm{Zn}}$. As discussed in the main text, our hypothesis for the cause of the strong observed ferromagnetism is the presence of a high concentration of unpassivated $\mathrm{V}_{\mathrm{Zn}}$, which are most likely initially present in the material as $\mathrm{H}$-passivated $\mathrm{V}_{\mathrm{Zn}}$ (likely in the form of neutral $\mathrm{V}_{\mathrm{Zn}}+2 \mathrm{H}$ based on the work of Frodason et al. ${ }^{20,21}$ and our calculations for bulk $\mathrm{ZnO}$ in Section S11), with the $\mathrm{H}$ subsequently removed via annealing in Ar.

\section{S11. Calculated neutral defect formation energies and magnetic moments in bulk $\mathrm{ZnO}$}

Fig. S13 contains plots of the $\mathrm{V}_{\mathrm{Zn}}$ defect formation energy in bulk $\mathrm{ZnO}$ for dilute unpassivated $\mathrm{V}_{\mathrm{Zn}}$ and $\mathrm{V}_{\mathrm{Zn}}$ passivated with varying amount of $\mathrm{H}$. As discussed in Section S10, calculating all defects as neutral is appropriate based on the findings of Frodason et al., who found that the stable defect is either neutral $\mathrm{V}_{\mathrm{Zn}}+2 \mathrm{H}$ (H present) or neutral $\mathrm{V}_{\mathrm{Zn}}$ (no $\mathrm{H}$ present). In Fig. S13, it is clear that passivation of the dangling $\mathrm{O}$ bonds in the $\mathrm{V}_{\mathrm{Zn}}$ defect with $\mathrm{H}$ has a dramatic impact on the defect formation energy. The formation energy of unpassivated $V_{Z n}$ is $3.75 \mathrm{eV} / \mathrm{V}_{\mathrm{Zn}}$. Passivating the $\mathrm{V}_{\mathrm{Zn}}$ with $\mathrm{H}$ resulted in a reduction in the formation energy by more than $1 \mathrm{eV} / \mathrm{V}_{\mathrm{Zn}}$ for each of the first $2 \mathrm{H}$ present in the defect, for a minimum value of $0.62 \mathrm{eV} / \mathrm{V}_{\mathrm{Zn}}$ when $2 \mathrm{H}$ fully passivate the defect. When additional $\mathrm{H}$ atoms beyond $2 \mathrm{H} / \mathrm{V}_{\mathrm{Zn}}$ were added, the formation energy increases. This trend can be understood from charge balance arguments. The removal of one $\mathrm{Zn}$ doped the system with two holes. Adding $2 \mathrm{H}$ to the $\mathrm{V}_{\mathrm{Zn}}$ doped the system with 2 electrons, resulting in a charge neutral system. Additional $\mathrm{H}$ content beyond $2 \mathrm{H} / \mathrm{V}_{\mathrm{Zn}}$ resulted in additional electron doping, which resulted in an energy penalty and a less stable defect. These findings that unpassivated $\mathrm{V}_{\mathrm{Zn}}$ have a relatively high formation energy is consistent with a number of previous DFT studies. ${ }^{19-22,33,42-45}$ The fact that the formation energy can be significantly lowered by the introduction of $\mathrm{H}$ is consistent with the DFT study by Peng et al. ${ }^{33}$ (note that in the study of Peng et al., only a single $\mathrm{H}$ atom was used to passivate the $\mathrm{V}_{\mathrm{Zn}}$ defect) and the DFT study of Frodason et $a l^{20}$. Overall, the $\mathrm{V}_{\mathrm{Zn}}$ formation energies reported in Fig. S13 match very well with those reported in the work of Frodason et al. We note here that in the work of Frodason et al., the reference states of the $\mathrm{O}, \mathrm{Zn}$ and $\mathrm{H}$ chemical potentials were the same as this work $\left(\mathrm{O}_{2}\right.$ gas for $\mathrm{O}, \mathrm{ZnO}$ for $\mathrm{Zn}, \mathrm{H}_{2} \mathrm{O}$ for $\left.\mathrm{H}\right)$ but the chemical potential values were not shifted based on the corrections of Nørskov et al. ${ }^{40}$ and 
Man et al. ${ }^{41}$ (summarized in Table S3). In order to draw an accurate comparison between this work and Frodason et al. in Fig S13, we have shifted the reported defect formation energies from Frodason et al. by the appropriate chemical potential shifts from Table S3.

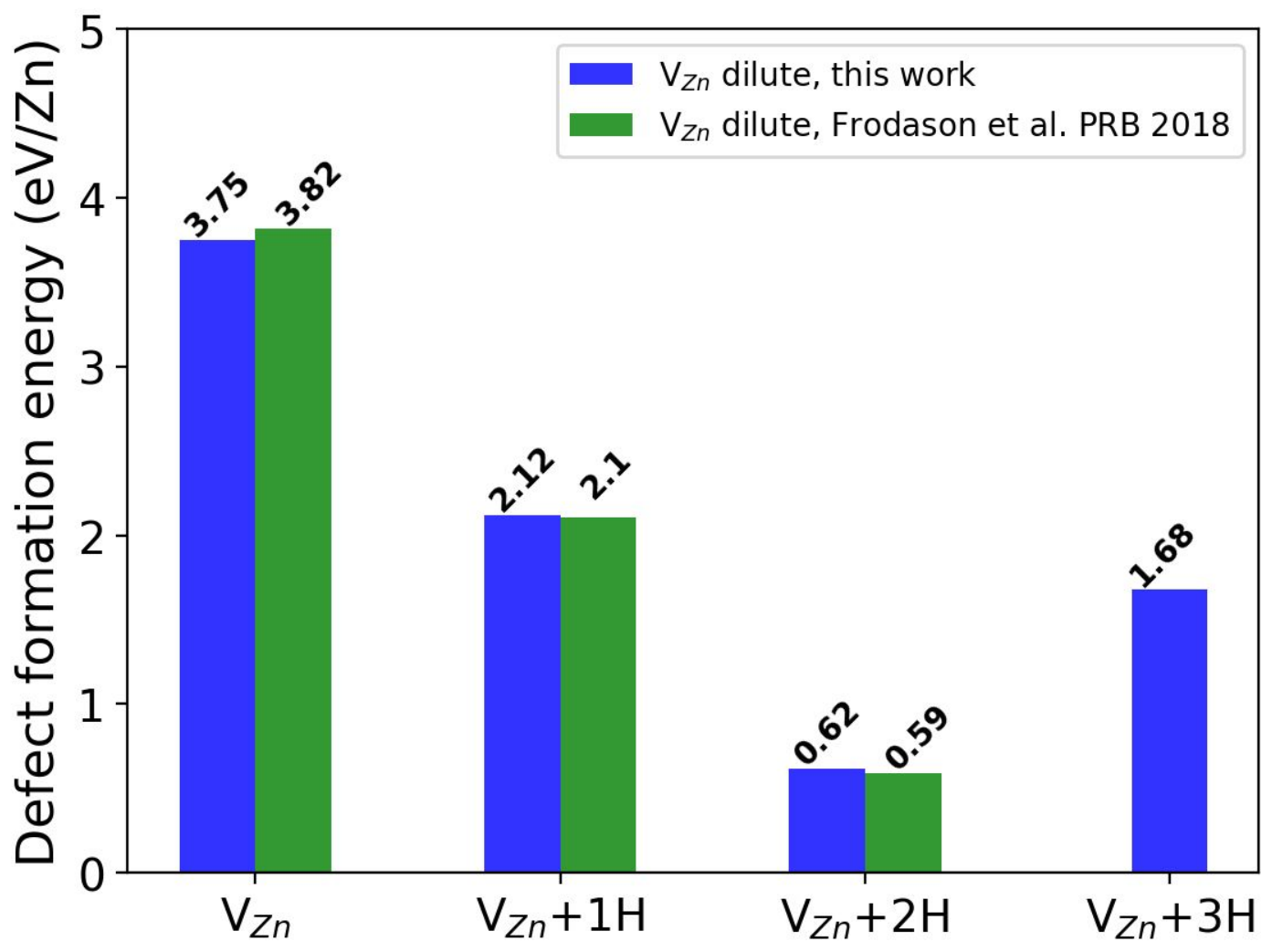

Fig. S13. Bulk $\mathrm{ZnO}$ dilute defect formation energy of $\mathrm{V}_{\mathrm{Zn}}$ for varying amounts of $H$ passivation. Dilute $\mathrm{V}_{\mathrm{Zn}}$ defect formation energy calculations in this work (blue) and the work of Frodason et al. (green). ${ }^{6}$ Note that the work of Frodason et al. did not apply the chemical potential shifts summarized in Table $\mathrm{S} 3$ of this work. Therefore, to make a meaningful comparison between this work and Frodason et al., we extracted the formation energies reported in Frodason et al. and applied the chemical potential shifts summarized in Table S3.

Table S4 summarizes the calculated magnetic moments for the dilute $\mathrm{V}_{\mathrm{Zn}}$ defects shown in Fig. S13. Unpassivated $V_{Z n}$ defects display a strong magnetic moment of $2.00 \mu_{B} / V_{Z n}$ from HSE calculations in this work. However, $\mathrm{H}$ passivation resulted in the elimination of the magnetic moment. As discussed in the main text, the fact that unpassivated $\mathrm{V}_{\mathrm{Zn}}$ is the source of magnetism in $\mathrm{ZnO}$ is consistent with a number of previous studies. ${ }^{33}, 42,44,46-49$ The HSE calculations in this work display the largest magnetic moment for unpassivated $V_{Z n}$ of $2.00 \mu_{B} / V_{Z n}$, while GGA 
calculations of Peng et al. result in $1.73 \boldsymbol{\mu}_{\mathrm{B}} / \mathrm{V}_{\mathrm{Zn}}$ and GGA $+U$ calculations of Adeagbo et al. and Lin et al. result in $1.89 \mu_{\mathrm{B}} / \mathrm{V}_{\mathrm{Zn}}$ and $1.65 \mu_{\mathrm{B}} / \mathrm{V}_{\mathrm{Zn}}$, respectively. Adding a single $\mathrm{H}$ atom to $\mathrm{V}_{\mathrm{Zn}}$ reduces the HSE-calculated moment to $1.00 \boldsymbol{\mu}_{\mathrm{B}} / \mathrm{V}_{\mathrm{Zn}}$. The reduction of the moment with adding a single $\mathrm{H}$ atom to $\mathrm{V}_{\mathrm{Zn}}$ has also been observed from GGA calculations in Peng et al. $\left(0.99 \mu_{\mathrm{B}} / \mathrm{V}_{\mathrm{Zn}}\right)$ and from GGA $+U$ calculations in Adeagbo et al. $\left(1.03 \mu_{\mathrm{B}} / \mathrm{V}_{\mathrm{Zn}}\right)$. When the $\mathrm{V}_{\mathrm{Zn}}$ is further passivated to contain $2 \mathrm{H}$ atoms, the magnetic moment is eliminated. The elimination of the magnetic moment with $\mathrm{H}$ passivation is expected, as the moment induced by the formation of $\mathrm{V}_{\mathrm{Zn}}$ is localized to the dangling $\mathrm{O}$ bonds in the $\mathrm{V}_{\mathrm{Zn}}$ defect. Thus, including $\mathrm{H}$ in the $\mathrm{V}_{\mathrm{Zn}}$ defects passivated the dangling bonds, doped 2 electrons to cancel out the 2 holes produced by the $\mathrm{V}_{\mathrm{Zn}}$, and quenched the magnetic moment.

Table S4. Bulk ZnO magnetic moments. Summary of magnetic moments for bulk dilute $\mathrm{V}_{\mathrm{Zn}}$ defect structures examined in this work.

\begin{tabular}{|c|c|}
\hline Defect & Calculated magnetic moment $\left(\boldsymbol{\mu}_{\mathbf{B}} / \mathbf{V}_{\mathbf{Z n}}\right)$ \\
\hline & $\begin{array}{c}2.00 \text { (this work, HSE), } 1.73 \text { (Peng } \text { et al., } \\
\left.\text { GGA) }{ }^{33} 1.89 \text { (Adeagbo } \text { et al., GGA }+U\right),{ }^{46} \\
1.65 \text { (Lin } \text { et al., GGA }+U)^{47}\end{array}$ \\
\hline $\mathrm{V}_{\mathrm{Zn}}+1 \mathrm{H}$ & $\begin{array}{c}1.00 \text { (this work, HSE), } 0.99 \text { (Peng } \text { et al., } \\
\left.\text { GGA) }{ }^{33} 1.03 \text { (Adeagbo } \text { et al., GGA }+U\right)^{46}\end{array}$ \\
\hline $\mathrm{V}_{\mathrm{Zn}}+2 \mathrm{H}$ & 0.00 (this work, HSE) \\
\hline $\mathrm{V}_{\mathrm{Zn}}+3 \mathrm{H}$ & 0.00 (this work, HSE) \\
\hline
\end{tabular}

Fig S14 shows the defect formation energies of unpassivated $\mathrm{V}_{\mathrm{Zn}}$ and passivated $\mathrm{V}_{\mathrm{Zn}}+2 \mathrm{H}$ for cases where the $\mathrm{V}_{\mathrm{Zn}}$ are dilute, and have higher concentrations of $22 \%$ and $33 \%$. The concentration of $33 \%$ was chosen based on the experimental EELS results indicating that approximately one-third of the $\mathrm{Zn}$ atoms were missing, and the lower concentration of $22 \%$ was chosen to investigate an intermediate but still high value of Zn vacancy content between the dilute limit and the high 33\% value indicated from the experiments. While it may be possible to realize an even greater than $33 \%$ $\mathrm{V}_{\mathrm{Zn}}$ concentration, our current investigation of the $33 \%$ concentration structures were motivated by the experimental EELS results and analysis of higher concentrations has not been investigated at this time. Here, we remark on the differences in formation energy between dilute $V_{\mathrm{Zn}}$ and the 
higher concentration $\mathrm{V}_{\mathrm{Zn}}$ values. For the unpassivated $\mathrm{V}_{\mathrm{Zn}}$, there is a clear reduction in defect formation energy of about $600 \mathrm{meV} / \mathrm{V}_{\mathrm{Zn}}\left(800 \mathrm{meV} / \mathrm{V}_{\mathrm{Zn}}\right)$ for the $22 \% \mathrm{~V}_{\mathrm{Zn}}\left(33 \% \mathrm{~V}_{\mathrm{Zn}}\right)$ cases compared to the formation energy of dilute $\mathrm{V}_{\mathrm{Zn}}$. Note that the values of the bulk $33 \%$ defect formation energies are averaged over 3 orderings for $V_{Z n}$ ("criss-cross", "staggered", "screw" configurations) and over 4 orderings for $\mathrm{V}_{\mathrm{Zn}}+2 \mathrm{H}$ ("criss-cross", "staggered", "screw" and "layered" configurations), where the defect formation energies in Fig S14 are the average values and the error bars denote the maximum and minimum calculated values. The "layered" structure with unpassivated $\mathrm{V}_{\mathrm{Zn}}$ underwent significant distortions to the point where the material no longer appeared to be fully wurtzite $\mathrm{ZnO}$ and was therefore eliminated from the average defect formation energy calculation. We note here this "layered" structure was more stable by about $100 \mathrm{meV} / \mathrm{V}_{\mathrm{Zn}}$ than the other $33 \% \mathrm{~V}_{\mathrm{Zn}}$ structures. However, the large extent of the structural distortions suggest that attaining this structure is likely to be kinetically inhibited. There are two bulk $33 \% \mathrm{~V}_{\mathrm{Zn}}+2 \mathrm{H}$ values that are negative: "criss-cross" and "staggered", both of which have a defect formation energy of $-0.02 \mathrm{eV} / \mathrm{V}_{\mathrm{Zn}}$. This result indicates that a very high concentration of $33 \% \mathrm{~V}_{\mathrm{Zn}}$, in two different arrangements, both have a negative (or nearly so, within DFT calculation errors) defect formation energy, indicating the formation of this high defect concentration (when passivated with $\mathrm{H}$ ) is potentially thermodynamically stable in the bulk. Therefore, we predict here it is likely $\mathrm{ZnO}$ can realize a high concentration of $\mathrm{V}_{\mathrm{Zn}}$ passivated with $\mathrm{H}$ under the growth conditions of this study. From the results and discussion in the main text, electron energy loss spectroscopy (EELS) measurements demonstrate that the $\mathrm{ZnO}$ nanosheets grown in this study are indeed missing approximately one-third of the $\mathrm{Zn}$ atoms, confirming the plausibility of the high concentration of $\mathrm{V}_{\mathrm{Zn}}$ predicted here. Note that we do not know experimentally the precise structure of the $\mathrm{ZnO}$ nanosheets that are missing approximately one-third of the $\mathrm{Zn}$ atoms. Therefore, we consider the $33 \% \mathrm{~V}_{\mathrm{Zn}}$ structures simulated here to be a qualitative guide of the effect of high concentrations of $\mathrm{V}_{\mathrm{Zn}}$ on the defect formation energy and associated magnetic behavior, and not indicative of a quantitively solved structure of highly defected $\mathrm{ZnO}$ under these growth conditions. The stabilization of the $\mathrm{V}_{\mathrm{Zn}}$ at higher concentrations suggests that they have a stabilizing interaction on each other, and this has been seen even at the level of just two defects in the literature. ${ }^{45,50}$ The source of this stabilization is not clear at this time and is an important topic for further research. 


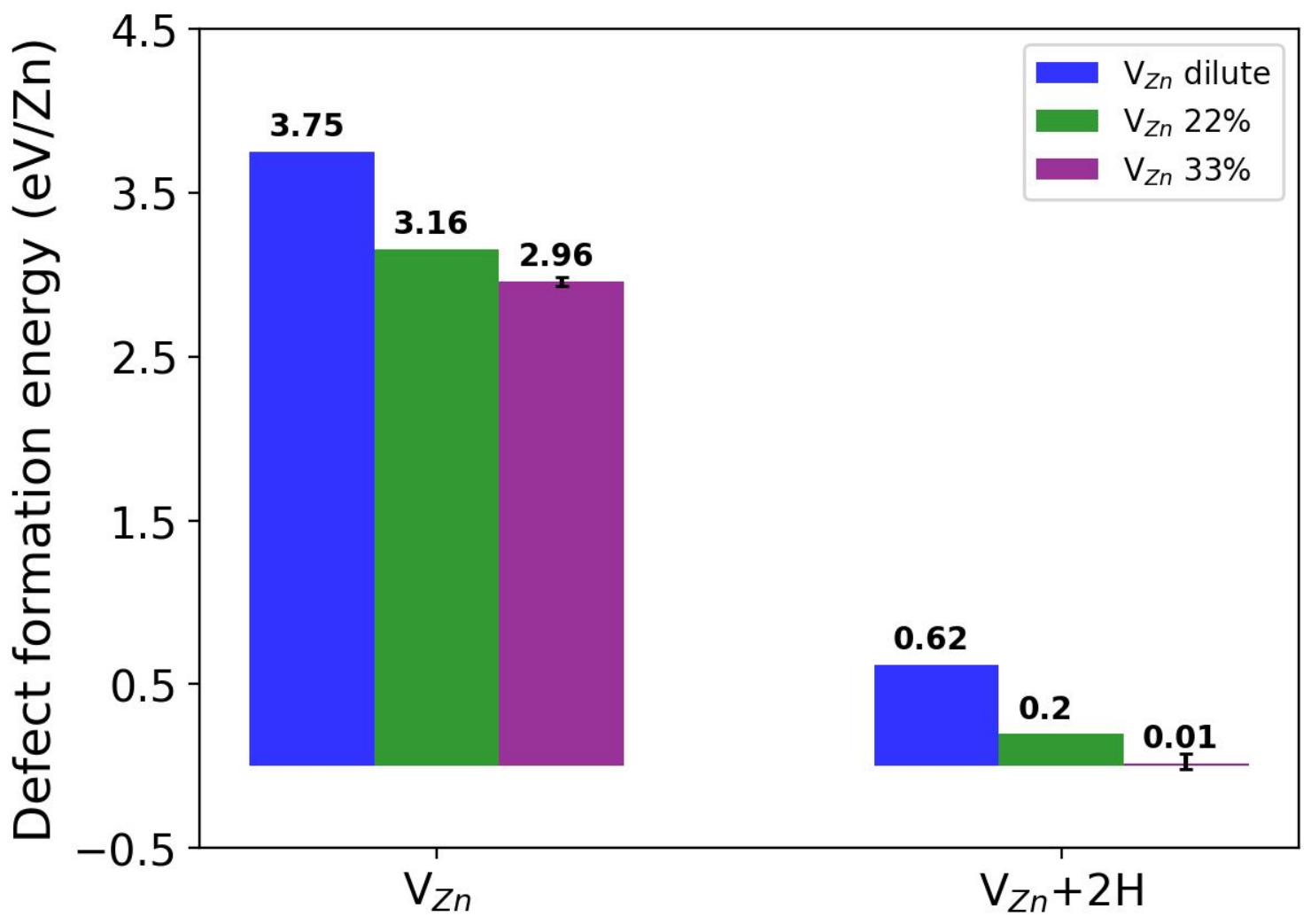

Fig. S14. Dilute, $22 \%$ and $33 \% \mathrm{~V}_{\mathrm{Zn}}$ defect formation energies for bulk $\mathrm{ZnO}$. Defect formation energies of unpassivated $\mathrm{V}_{\mathrm{Zn}}$ and passivated $\mathrm{V}_{\mathrm{Zn}}+2 \mathrm{H}$ defects in bulk $\mathrm{ZnO}$ : dilute $\mathrm{V}_{\mathrm{Zn}}$ (blue bars), $22 \% \mathrm{~V}_{\mathrm{Zn}}$ (green bars), and $33 \% \mathrm{~V}_{\mathrm{Zn}}$ (purple bars). The values of the bulk 33\% defect formation energies are averaged over 3 orderings ( $\mathrm{V}_{\mathrm{Zn}}$ : “criss-cross", "staggered”, "screw” configurations) and over 4 orderings $\left(\mathrm{V}_{\mathrm{Zn}}+2 \mathrm{H}\right.$ : "criss-cross", "staggered", "screw" and "layered" configurations), where the black number denotes the average value and the error bars denote the maximum and minimum calculated values. There are two bulk $33 \% \mathrm{~V}_{\mathrm{Zn}}+2 \mathrm{H}$ is values that are negative: "crisscross" and "staggered", both of which have a defect formation energy of $-0.02 \mathrm{eV} / \mathrm{V}_{\mathrm{Zn}}$.

\section{S12. Calculated neutral defect formation energies and magnetic moments in $\mathrm{ZnO}$ surface and grain boundary structures}

Our simulation of defects in $\mathrm{ZnO}$ surface slab and grain boundaries is motivated by our desire to understand the qualitative effects of the surface or grain boundary on the defect formation energy relative to the bulk defect formation energy, in order to explain the experimental observations that a higher $\mathrm{ZnO}$ magnetization can be achieved when the $\mathrm{ZnO}$ nanosheets are polycrystalline (water- 
oil interface in synthesis, $50.9 \mathrm{emu} / \mathrm{g}$ at room temperature) compared to when the $\mathrm{ZnO}$ nanosheets are single crystals (water-air interface in synthesis, $35.0 \mathrm{emu} / \mathrm{g}$ at room temperature). Again, as discussed and justified in Section S10 we use only neutral defects.

Fig. S15 contains a plot of the defect formation energy of unpassivated and H-passivated $\mathrm{V}_{\mathrm{Zn}}$ at dilute and 33\% defect concentrations for bulk and the (0001) surface slab of $\mathrm{ZnO}$. There are a few comparisons that can be drawn from the data in Fig S15. First, we remark on the differences in formation energy for dilute $\mathrm{V}_{\mathrm{Zn}}$ between the bulk and surface slab. By comparing the $\mathrm{V}_{\mathrm{Zn}}$ formation energy in the slab versus the bulk, it is clear $\mathrm{V}_{\mathrm{Zn}}+2 \mathrm{H}$ are generally easier to form near the $\mathrm{ZnO}$ surface, with $\mathrm{V}_{\mathrm{Zn}}+2 \mathrm{H}$ about $370 \mathrm{meV} / \mathrm{V}_{\mathrm{Zn}}$ easier to form compared to the bulk $\mathrm{V}_{\mathrm{Zn}}+2 \mathrm{H}$. However, the unpassivated $\mathrm{V}_{\mathrm{Zn}}$ is about $100 \mathrm{meV} / \mathrm{V}_{\mathrm{Zn}}$ higher than the respective bulk formation energy. It is unclear why the $\mathrm{V}_{\mathrm{Zn}}+2 \mathrm{H}$ is easier to form (compared to bulk) near the surface while the unpassivated $\mathrm{V}_{\mathrm{Zn}}$ is harder to form (compared to bulk). However, we note here that only a single site for the $V_{Z n}$ in the surface slab was simulated, and $V_{Z n}$ sites either further from the $\mathrm{Zn}$ terminated surface, or near the O-terminated surface may have lower formation energies than what is reported here. Further, it is worth noting that the reconstruction used to model the O-terminated surface (based on work from Jacobs et al. $)^{24}$ already has one-third of the $\mathrm{Zn}$ sites in the $\mathrm{Zn}$ layer beneath the O-terminated surface vacant, prior to the introduction of the additional $\mathrm{V}_{\mathrm{Zn}}$ near the $\mathrm{Zn}$-terminated surface. The stability of this reconstruction may indicate a driving force for $\mathrm{V}_{\mathrm{Zn}}$ to preferentially form near the O-terminated surface, and in a manner that facilitates their enhanced formation near the surface relative to the bulk.

Second, we remark on the differences in formation energy between dilute $\mathrm{V}_{\mathrm{Zn}}$ and the $33 \% \mathrm{~V}_{\mathrm{Zn}}$ values. For the bulk unpassivated (H-passivated) $\mathrm{V}_{\mathrm{Zn}}$, the strong reduction in defect formation energy of about $800 \mathrm{meV} / \mathrm{V}_{\mathrm{Zn}}\left(600 \mathrm{meV} / \mathrm{V}_{\mathrm{Zn}}\right)$ for the $33 \% \mathrm{~V}_{\mathrm{Zn}}$ bulk structures compared to the dilute $\mathrm{V}_{\mathrm{Zn}}$ in the bulk was discussed above in Section $\mathrm{S} 11$. In addition, the $33 \% \mathrm{~V}_{\mathrm{Zn}}$ values in the surface slab are also more stable than the dilute $\mathrm{V}_{\mathrm{Zn}}$ formation energies in the surface slab, where the unpassivated (H-passivated) $\mathrm{V}_{\mathrm{Zn}}$ are reduced by $950 \mathrm{meV} / \mathrm{V}_{\mathrm{Zn}}\left(180 \mathrm{meV} / \mathrm{V}_{\mathrm{Zn}}\right)$ for the $33 \% \mathrm{~V}_{\mathrm{Zn}}$ in the surface slab compared to the dilute $V_{Z n}$ in the surface slab. 
Finally, we remark on the differences in formation energy for the $33 \% \mathrm{~V}_{\mathrm{Zn}}$ between the bulk and surface slab. For unpassivated $33 \% \mathrm{~V}_{\mathrm{Zn}}$, the surface slab shows a slight reduction compared to the bulk of about $60 \mathrm{meV} / \mathrm{V}_{\mathrm{Zn}}$. For the passivated $33 \% \mathrm{~V}_{\mathrm{Zn}}+2 \mathrm{H}$, the defect formation energy is about $60 \mathrm{meV} / \mathrm{V}_{\mathrm{Zn}}$ higher than the average of the $33 \% \mathrm{~V}_{\mathrm{Zn}}$ bulk arrangements. While this higher value of $33 \% \mathrm{~V}_{\mathrm{Zn}}+2 \mathrm{H}$ in the surface slab compared to the bulk may be the result of only attempting a single $\mathrm{V}_{\mathrm{Zn}}$ ordering (the "criss-cross" structure), since the "criss-cross" structure was stable (-0.02 $\mathrm{eV} / \mathrm{VZn}$ ) in the bulk, we speculate the $\mathrm{V}_{\mathrm{Zn}}+2 \mathrm{H}$ may be less stable in the surface slab because the reconstructions used for both the O-terminated and $\mathrm{Zn}$-terminated surfaces may no longer be the stable reconstructions for such a highly defected form of $\mathrm{ZnO}$. The reconstructions used in this work were found from previous studies which used surface slabs that were stoichiometric $\mathrm{ZnO}$. Further experimental evidence detailing the surface reconstructions of these nanosheets, the structure of the highly concentrated $\mathrm{V}_{\mathrm{Zn}}$ within the nanosheets, or more thorough DFT investigations of the stability of surface reconstructions for highly defective $\mathrm{ZnO}$ would be required to more quantitatively investigate this issue, which is beyond the scope of the current work.

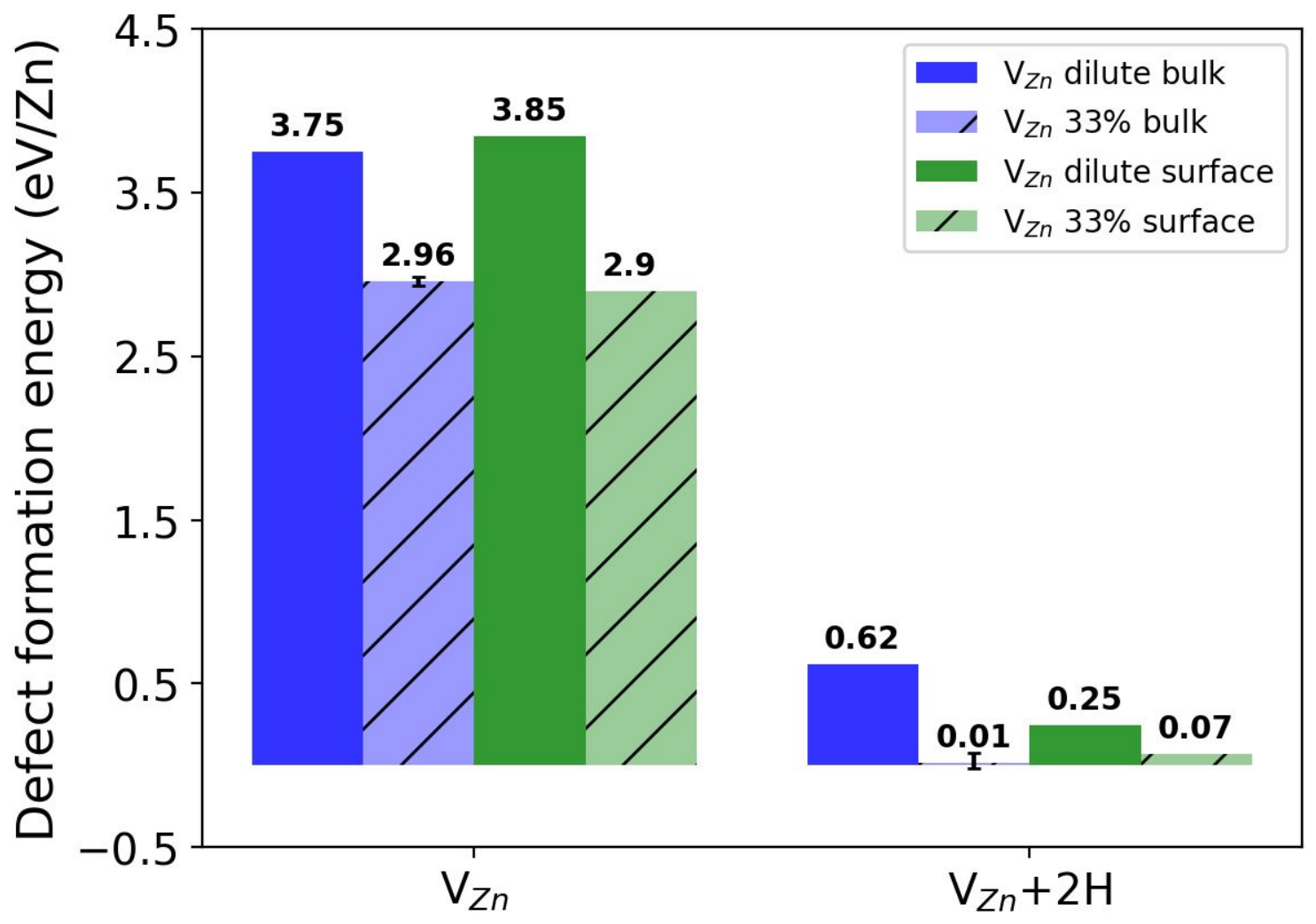


Fig. S15. Dilute and $33 \% \mathrm{~V}_{\mathrm{Zn}}$ defect formation energies for bulk and surface slab. Nearsurface $\mathrm{ZnO}$ defect formation energy of $\mathrm{V}_{\mathrm{Zn}}$ for dilute unpassivated $\mathrm{V}_{\mathrm{Zn}}$ and passivated $\mathrm{V}_{\mathrm{Zn}}+2 \mathrm{H}$ in the bulk (solid blue bars) and in the sub-surface Zn-terminated (0001) ZnO surface (solid green bars) and $33 \%$ ordered $\mathrm{V}_{\mathrm{Zn}}$ in the bulk (hashed blue bars) and in the (0001) ZnO surface slab (hashed green bars). The values of the bulk 33\% defect formation energies are averaged over 3 orderings ( $\mathrm{V}_{\mathrm{Zn}}$ : “criss-cross", "staggered", "screw" configurations) and over 4 orderings $\left(\mathrm{V}_{\mathrm{Zn}}+2 \mathrm{H}\right.$ : “criss-cross", "staggered", "screw" and "layered" configurations), where the black number denotes the average value and the error bars denote the maximum and minimum calculated values. There are two bulk $33 \% \mathrm{~V}_{\mathrm{Zn}}+2 \mathrm{H}$ is values that are negative: "criss-cross" and "staggered", both of which have a defect formation energy of $-0.02 \mathrm{eV} / \mathrm{V}_{\mathrm{Zn}}$.

Table S5 contains the calculated magnetic moments for the dilute and $33 \%$ surface $\mathrm{V}_{\mathrm{Zn}}$ defects simulated in this work. The corresponding bulk magnetic moments for the respective defects are also provided for comparison. In Table S5, for the dilute $V_{Z n}$ defects, the moment of the unpassivated $\mathrm{V}_{\mathrm{Zn}}$ was $2.00 \boldsymbol{\mu}_{\mathrm{B}} / \mathrm{V}_{\mathrm{Zn}}$, which is equal to the bulk value. It is not clear if a change of moment from the bulk value (whether reduced or enhanced) may be possible based on the chosen site of the $\mathrm{V}_{\mathrm{Zn}}$ defect (for example, near the $\mathrm{O}$-terminated or equidistant from the O-terminated and $\mathrm{Zn}$-terminated surfaces). However, more detailed studies of the surface magnetism induced by these $\mathrm{V}_{\mathrm{Zn}}$ defects would be required if more quantitative understanding is desired.

Table S5. Dilute and $33 \% \mathbf{V}_{\mathrm{Zn}}$ magnetic moments. Summary of magnetic moments for nearsurface $\mathrm{V}_{\mathrm{Zn}}$ defects examined in this work. The magnetic moment values listed in the parentheses are the calculated bulk values from Table S4, provided here for reference.

\begin{tabular}{|c|c|c|}
\hline $\begin{array}{c}\text { Defect } \\
\text { group }\end{array}$ & Defect & Calculated magnetic moment $\left(\boldsymbol{\mu}_{\mathbf{B}} / \mathbf{V}_{\mathbf{Z n}}\right)$ \\
\hline Fig. S14 & $\mathrm{V}_{\mathrm{Zn}}$ & $2.00(2.00)$ \\
\cline { 2 - 3 }$\left(\right.$ dilute $\left.\mathrm{V}_{\mathrm{Zn}}\right)$ & $\mathrm{V}_{\mathrm{Zn}}+2 \mathrm{H}$ & $0.00(0.00)$ \\
\hline Fig. S14 & $\mathrm{V}_{\mathrm{Zn}}$ & $2.00(2.00)$ \\
\cline { 2 - 3 }$\left(33 \% \mathrm{~V}_{\mathrm{Zn}}\right)$ & $\mathrm{V}_{\mathrm{Zn}}+2 \mathrm{H}$ & $0.05(0.00)$ \\
\hline
\end{tabular}


Fig. S16 contains plots of the defect formation energy of $\mathrm{V}_{\mathrm{Zn}}$ for varying $\mathrm{H}$ content in various grain boundary structures of $\mathrm{ZnO}$ for unpassivated $\mathrm{V}_{\mathrm{Zn}}$ (blue bars) and passivated $\mathrm{V}_{\mathrm{Zn}}+2 \mathrm{H}$ (green bars). The dilute $\mathrm{V}_{\mathrm{Zn}}$ and $\mathrm{V}_{\mathrm{Zn}}+2 \mathrm{H}$ defect formation energies from the bulk and surface slab cases are provided as a reference. We note here that the formation of a defect within a grain boundary structure should have a distribution of values due to the high number of inequivalent lattice sites. However, in this work we were only interested in the qualitative effect some commonly observed grain boundary structures may have on the formation energy and magnetic moment of $\mathrm{V}_{\mathrm{Zn}}$ defects. Therefore, no effort was made to enumerate all possible indistinct $\mathrm{Zn}$ sites in each grain boundary structures, and instead a single calculation was performed for each defect type and each grain boundary structure. Therefore, more detailed studies of the formation energies and resulting magnetism of $\mathrm{V}_{\mathrm{Zn}}$ defects in these grain boundary structures may be warranted if more quantitative understanding is desired. The grain boundary structures and notation used to denote each grain boundary follows the studies of Körner et al. ${ }^{27-29}$ From Fig. S16, it is clear the formation energy of $\mathrm{V}_{\mathrm{Zn}}$ is reduced within a grain boundary, sometimes on the scale of a couple $\mathrm{eV}$. This large reduction in the $\mathrm{V}_{\mathrm{Zn}}$ formation energy occurred for both passivated and unpassivated $\mathrm{V}_{\mathrm{Zn}}$. The lower formation energies of $\mathrm{V}_{\mathrm{Zn}}$ defects within grain boundaries compared to bulk $\mathrm{ZnO}$ provides a straightforward explanation for the fact that we observed a larger magnetization in the polycrystalline $\mathrm{ZnO}$ nanosheets in this study compared to the single crystalline nanosheets. The introduction of grain boundaries enhanced the ferromagnetic response of the material by enabling the creation of more $\mathrm{V}_{\mathrm{Zn}}$ than the single crystalline case.

Table S6 summarizes the calculated magnetic moments for the unpassivated $\mathrm{V}_{\mathrm{Zn}}$ and passivated $\mathrm{V}_{\mathrm{Zn}}+2 \mathrm{H}$ defects in each type of grain boundary structure simulated in this work. For GB1, GB2b, GB2c, and GB2d, the unpassivated $V_{Z n}$ have the same moment value as the $V_{Z n}$ in bulk $Z n O$, i.e. $2.00 \boldsymbol{\mu}_{\mathrm{B}} / \mathrm{V}_{\mathrm{Zn}}$. Meanwhile, GB6 and GB7 have no moment. It is unclear why these grain boundaries do not display a moment even for the case of unpassivated $\mathrm{V}_{\mathrm{Zn}}$. We speculate that due the disordered nature of the grain boundary region (particularly for these lower angle, higher $\Sigma$ GB6 and GB7 grain boundaries), the local $\mathrm{O}$ dangling bond environment of the $\mathrm{V}_{\mathrm{Zn}}$ differs sufficiently from the bulk such that the $\mathrm{d}^{0}$-characteristic moment is not stable on the unbonded $\mathrm{O} 2 p$ orbitals. It is possible that different $\mathrm{V}_{\mathrm{Zn}}$ sites in the GB6 and GB7 structures would yield a nonzero magnetic moment, however this was not further investigated due to the computational expense of these 
calculations. More thorough investigations of the magnetic behavior of $\mathrm{V}_{\mathrm{Zn}}$ in $\mathrm{ZnO}$ grain boundaries may shed additional light on these physics. Regardless, based on the defect formation energies depicted in Fig. S16 showing that $\mathrm{V}_{\mathrm{Zn}}$ are generally easier to form at grain boundaries compared to bulk, together with the fact that most grain boundaries examined here show the same magnetic moment as $\mathrm{V}_{\mathrm{Zn}}$ in bulk $\mathrm{ZnO}$, further indicates that the presence of grain boundaries likely enhances the overall magnetization of the polycrystalline (compared to single crystal) $\mathrm{ZnO}$ nanosheets studied in this work.

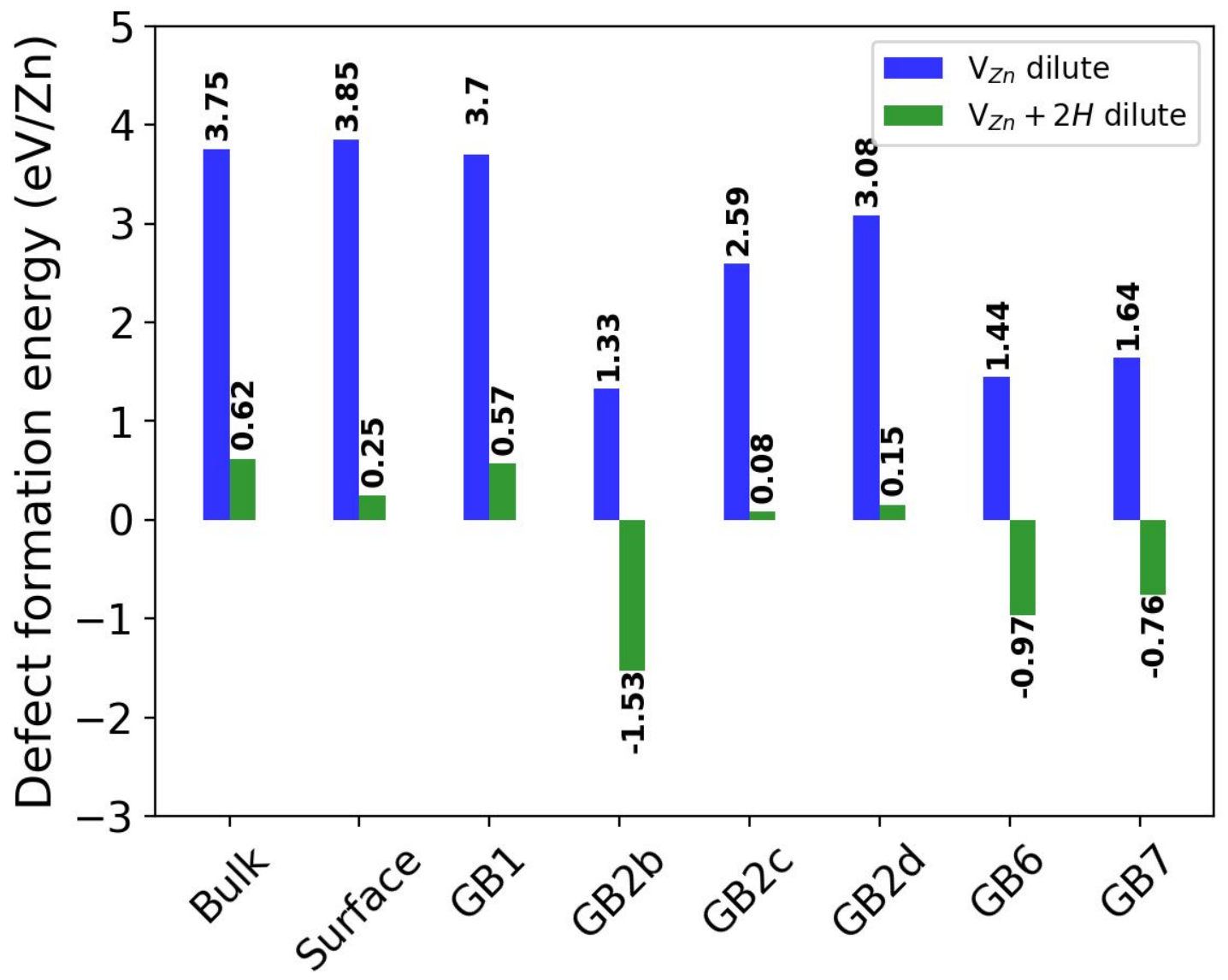

Fig. S16. Summary of dilute $V_{\mathrm{Zn}}$ formation in grain boundary structures with comparison to bulk and surface slab. $\mathrm{ZnO}$ grain boundary defect formation energy of both unpassivated $\mathrm{V}_{\mathrm{Zn}}$ (blue bars) and passivated $\mathrm{V}_{\mathrm{Zn}}+2 \mathrm{H}$ (green bars) for 6 different grain boundary structures obtained from the works of Körner et al. ${ }^{27-29}$ The values of defect formation energy for bulk and surface slab cases are provided as a reference. 
Table S6. Dilute $\mathbf{V}_{\mathrm{Zn}}$ magnetic moments in grain boundaries. Summary of magnetic moments for grain boundary $\mathrm{V}_{\mathrm{Zn}}$ defect structures examined in this work. The notation to denote each grain boundary structure is the same as that used in Körner et al. ${ }^{27-29}$ The magnetic moment values listed in the parentheses are the calculated bulk values from Table S4, provided here for reference.

\begin{tabular}{|c|c|c|}
\hline \multirow{2}{*}{ Grain boundary } & Defect & $\begin{array}{c}\text { Calculated magnetic moment } \\
\left(\boldsymbol{\mu}_{\mathbf{B}} / \mathbf{V}_{\mathbf{Z n}}\right)\end{array}$ \\
\hline \multirow{2}{*}{ GB1 } & $\mathrm{V}_{\mathrm{Zn}}$ & $2.00(2.00)$ \\
\cline { 2 - 3 } & $\mathrm{V}_{\mathrm{Zn}}+2 \mathrm{H}$ & $0.00(0.00)$ \\
\hline \multirow{2}{*}{ GB2b } & $\mathrm{V}_{\mathrm{Zn}}$ & $2.00(2.00)$ \\
\cline { 2 - 3 } & $\mathrm{V}_{\mathrm{Zn}}+2 \mathrm{H}$ & $0.00(0.00)$ \\
\hline \multirow{2}{*}{ GB2c } & $\mathrm{V}_{\mathrm{Zn}}$ & $2.00(2.00)$ \\
\cline { 2 - 3 } & $\mathrm{V}_{\mathrm{Zn}}+2 \mathrm{H}$ & $0.00(0.00)$ \\
\hline \multirow{2}{*}{ GB2d } & $\mathrm{V}_{\mathrm{Zn}}$ & $2.00(2.00)$ \\
\cline { 2 - 3 } & $\mathrm{V}_{\mathrm{Zn}}+2 \mathrm{H}$ & $0.00(0.00)$ \\
\hline \multirow{2}{*}{ GB6 } & $\mathrm{V}_{\mathrm{Zn}}$ & $0.00(2.00)$ \\
\cline { 2 - 3 } & $\mathrm{V}_{\mathrm{Zn}}+2 \mathrm{H}$ & $0.00(0.00)$ \\
\hline \multirow{2}{*}{ GB7 } & $\mathrm{V}_{\mathrm{Zn}}$ & $0.00(2.00)$ \\
\cline { 2 - 3 } & $\mathrm{V}_{\mathrm{Zn}}+2 \mathrm{H}$ & $0.00(0.00)$ \\
\hline
\end{tabular}

\section{S13. The role of $\mathrm{H}$ in the magnetism of defected $\mathrm{ZnO}$, and annealing to remove $\mathrm{H}$}

As discussed in the main text, removal of the $\mathrm{H}$ from the passivated $\mathrm{V}_{\mathrm{Zn}}+2 \mathrm{H}$ defects is critical to enable strong ferromagnetic behavior. The removal of $\mathrm{H}$ was accomplished in this work by annealing the $\mathrm{ZnO}$ nanosheets in argon at $T=400{ }^{\circ} \mathrm{C}$ for 1 hour. A number of previous experimental studies have also shown that $\mathrm{H}$ can be removed from $\mathrm{ZnO}$ by annealing at comparable temperatures for 30-60 minutes in argon or vacuum. ${ }^{32,51-53}$ It is important to note that after annealing the large concentrations $\mathrm{V}_{\mathrm{Zn}}$ are no longer thermodynamically stable in air and are expected to anneal out if there is sufficient thermal energy to diffuse $\mathrm{Zn}$ in the system. Vacancy migration barriers under $p$-type conditions (which are expected with high $\mathrm{V}_{\mathrm{Zn}}$ concentrations during and after annealing) were predicted by DFT to be about 1-1.2 eV, ${ }^{54,55}$ which corresponds 
to about one $\mathrm{V}_{\mathrm{Zn}}$ hop over 1 hour at about $100^{\circ} \mathrm{C}$, although some experiments have shown that vacancy annealing does not complete until almost $700{ }^{\circ} \mathrm{C} .{ }^{56}$ Furthermore, vacancy mobility may be reduced from bulk unpassivated values by the presence of $\mathrm{H}$ during the annealing and/or the high vacancy concentrations and nanostructuring of the material. In addition, numerous studies have found that the migration barrier of interstitial $\mathrm{H}$ in $\mathrm{ZnO}$ has a very low barrier of $0.4-0.5 \mathrm{eV}$ calculated from DFT ${ }^{57,58}$ and about 0.2 obtained experimentally, ${ }^{59}$ indicating the $\mathrm{H}$ in the $\mathrm{V}_{\mathrm{Zn}}$ defects has a much lower barrier for diffusion than the $\mathrm{V}_{\mathrm{Zn}}$, implying the $\mathrm{H}$ will likely be expected to anneal out of the $\mathrm{ZnO}$ at a lower temperature (for some constant time), and generally at a time

before the $\mathrm{V}_{\mathrm{Zn}}$ may anneal out (at some particular temperature). The successful creation of high $\mathrm{M}_{\mathrm{s}}$ under $400{ }^{\circ} \mathrm{C}$ annealing in this work suggests that the $\mathrm{V}_{\mathrm{Zn}}$ do not move significantly at this temperature over 1 hour in the nanosheets, but the thermodynamic analysis done in this work suggests that annealing must be done carefully to ensure the $\mathrm{V}_{\mathrm{Zn}}$ are largely immobile.

\section{References}

1. Egerton, R. F. Springer. 3rd ed. New York: 2011.

2. $\quad$ Egerton, R. F.; Malac, M. Ultramicroscopy 2002, 92, (2), 47-56.

3. Schmid, N.; Eichenberger, A. P.; Choutko, A.; Riniker, S.; Winger, M.; Mark, A. E.; van Gunsteren, W. F. European biophysics journal 2011, 40, (7), 843.

4. Oostenbrink, C.; Villa, A.; Mark, A. E.; Van Gunsteren, W. F. Journal of computational chemistry 2004, 25, (13), 1656-1676.

5. Yin, X.; Shi, Y.; Wei, Y.; Joo, Y.; Gopalan, P.; Szlufarska, I.; Wang, X. Langmuir 2017, 33, (31), 7708-7714.

6. Sammalkorpi, M.; Karttunen, M.; Haataja, M. The Journal of Physical Chemistry B 2007, 111, (40), 11722-11733.

7. Schüttelkopf, A. W.; Van Aalten, D. M. Acta Crystallographica Section D: Biological Crystallography 2004, 60, (8), 1355-1363.

8. Berendsen, H.; Grigera, J.; Straatsma, T. Journal of Physical Chemistry 1987, 91, (24), 6269-6271.

9. Yin, Y.; Alivisatos, A. P. Nature 2005, 437, (7059), 664-670.

10. Peng, Y.-K.; Tsang, S. C. E. Nano Today 2018, 18, 15-34. 
11. Xu, S. J.; Li, G.; Chua, S. J.; Wang, X. C.; Wang, W. Applied Physics Letters 1998, 72, (19), 2451-2453.

12. Yang, D.-Q.; Rochette, J.-F.; Sacher, E. Langmuir 2005, 21, (18), 8539-8545.

13. Zeng, H.; Duan, G.; Li, Y.; Yang, S.; Xu, X.; Cai, W. Advanced Functional Materials 2010, 20, (4), 561-572.

14. Ischenko, V.; Polarz, S.; Grote, D.; Stavarache, V.; Fink, K.; Driess, M. Advanced Functional Materials 2005, 15, (12), 1945-1954.

15. Kresse, G.; Furthmüller, J. Physical Review B 1996, 54, (16), 11169-11186.

16. Kresse, G.; Joubert, D. Physical Review B 1999, 59, (3), 1758-1775.

17. Perdew, J. P.; Burke, K.; Ernzerhof, M. Physical Review Letters 1996, 77, (18), 3865-3868.

18. Heyd, J.; Scuseria, G. E.; Ernzerhof, M. The Journal of Chemical Physics 2003, 118, (18), 8207-8215.

19. Puchala, B.; Morgan, D. Physical Review B 2012, 85, (19), 195207.

20. Frodason, Y. K.; Johansen, K. M.; Bjørheim, T. S.; Svensson, B. G.; Alkauskas, A. Physical Review B 2018, 97, (10), 104109.

21. Frodason, Y. K.; Johansen, K. M.; Bjørheim, T. S.; Svensson, B. G.; Alkauskas, A. Physical Review B 2017, 95, (9), 094105.

22. Oba, F.; Togo, A.; Tanaka, I.; Paier, J.; Kresse, G. Physical Review B 2008, 77, (24), 245202 .

23. Reynolds, D. C.; Look, D. C.; Jogai, B.; Litton, C. W.; Cantwell, G.; Harsch, W. C. Physical Review B 1999, 60, (4), 2340-2344.

24. Jacobs, R.; Zheng, B.; Puchala, B.; Voyles, P. M.; Yankovich, A. B.; Morgan, D. The Journal of Physical Chemistry Letters 2016, 7, (22), 4483-4487.

25. Dulub, O.; Diebold, U.; Kresse, G. Physical Review Letters 2003, 90, (1), 016102.

26. Kresse, G.; Dulub, O.; Diebold, U. Physical Review B 2003, 68, (24), 245409.

27. Körner, W.; Elsässer, C. Physical Review B 2010, 81, (8), 085324.

28. Körner, W.; Elsässer, C. Physical Review B 2011, 83, (20), 205306.

29. Körner, W.; Bristowe, P. D.; Elsässer, C. Physical Review B 2011, 84, (4), 045305.

30. Kohan, A. F.; Ceder, G.; Morgan, D.; Van de Walle, C. G. Physical Review B 2000, 61, (22), 15019-15027.

31. Erhart, P.; Albe, K.; Klein, A. Physical Review B 2006, 73, (20), 205203. 
32. Lavrov, E. V.; Weber, J.; Börrnert, F.; Van de Walle, C. G.; Helbig, R. Physical Review B 2002, 66, (16), 165205.

33. Peng, C.; Liang, Y.; Wang, K.; Zhang, Y.; Zhao, G.; Wang, Y. The Journal of Physical Chemistry C 2012, 116, (17), 9709-9715.

34. Lavrov, E. V. Physica B: Condensed Matter 2003, 340-342, 195-200.

35. Yankovich, A. B.; Puchala, B.; Wang, F.; Seo, J.-H.; Morgan, D.; Wang, X.; Ma, Z.; Kvit, A. V.; Voyles, P. M. Nano Letters 2012, 12, (3), 1311-1316.

36. Van de Walle, C. G.; Neugebauer, J. Journal of Applied Physics 2004, 95, (8), 3851-3879.

37. Freysoldt, C.; Grabowski, B.; Hickel, T.; Neugebauer, J.; Kresse, G.; Janotti, A.; Van de Walle, C. G. Reviews of Modern Physics 2014, 86, (1), 253-305.

38. Jacobs, R. M.; Booske, J. H.; Morgan, D. Physical Review B 2012, 86, (5), 054106.

39. Janotti, A.; Van de Walle, C. G. Physical Review B 2007, 76, (16), 165202.

40. Nørskov, J. K.; Rossmeisl, J.; Logadottir, A.; Lindqvist, L.; Kitchin, J. R.; Bligaard, T.; Jónsson, H. The Journal of Physical Chemistry B 2004, 108, (46), 17886-17892.

41. Man, I. C.; Su, H.-Y.; Calle-Vallejo, F.; Hansen, H. A.; Martínez, J. I.; Inoglu, N. G.; Kitchin, J.; Jaramillo, T. F.; Nørskov, J. K.; Rossmeisl, J. ChemCatChem 2011, 3, (7), 1159-1165. 42. $\quad$ Wu, J.; Tang, X.; Long, F.; Tang, B. physica status solidi (b) 2017, 254, (6), 1600838.

43. Peng, C.; Wang, Y.; Cheng, Z.; Zhang, G.; Wang, C.; Yang, G. Physical Chemistry Chemical Physics 2015, 17, (25), 16536-16544.

44. Xing, G. Z.; Lu, Y. H.; Tian, Y. F.; Yi, J. B.; Lim, C. C.; Li, Y. F.; Li, G. P.; Wang, D. D.; Yao, B.; Ding, J.; Feng, Y. P.; Wu, T. AIP Advances 2011, 1, (2), 022152.

45. Wang, Q.; Sun, Q.; Chen, G.; Kawazoe, Y.; Jena, P. Physical Review B 2008, 77, (20), 205411.

46. Adeagbo, W. A.; Fischer, G.; Ernst, A.; Hergert, W. Journal of Physics: Condensed Matter 2010, 22, (43), 436002.

47. Lin, Q. L.; Li, G. P.; Xu, N. N.; Liu, H.; E, D. J.; Wang, C. L. The Journal of Chemical Physics 2019, 150, (9), 094704.

48. Hong, N. H.; Sakai, J.; Brizé, V. Journal of Physics: Condensed Matter 2007, 19, (3), 036219 . 
49. Khalid, M.; Ziese, M.; Setzer, A.; Esquinazi, P.; Lorenz, M.; Hochmuth, H.; Grundmann, M.; Spemann, D.; Butz, T.; Brauer, G.; Anwand, W.; Fischer, G.; Adeagbo, W. A.; Hergert, W.; Ernst, A. Physical Review B 2009, 80, (3), 035331.

50. Zubiaga, A.; Plazaola, F.; García, J. A.; Tuomisto, F.; Muñoz-Sanjosé, V.; Tena-Zaera, R. Physical Review B 2007, 76, (8), 085202.

51. Shi, G. A.; Stavola, M.; Pearton, S. J.; Thieme, M.; Lavrov, E. V.; Weber, J. Physical Review B 2005, 72, (19), 195211.

52. Lee, S. H.; Lee, T. S.; Lee, K. S.; Cheong, B.; Kim, Y. D.; Kim, W. M. Journal of Physics D: Applied Physics 2008, 41, (9), 095303.

53. Ip, K.; Overberg, M. E.; Heo, Y. W.; Norton, D. P.; Pearton, S. J.; Kucheyev, S. O.; Jagadish, C.; Williams, J. S.; Wilson, R. G.; Zavada, J. M. Applied Physics Letters 2002, 81, (21), 3996-3998.

54. $\quad$ Erhart, P.; Albe, K. Applied Physics Letters 2006, 88, (20), 201918.

55. Huang, G.-Y.; Wang, C.-Y.; Wang, J.-T. Solid State Communications 2009, 149, (5), 199204.

56. Parmar, N. S.; Boatner, L. A.; Lynn, K. G.; Choi, J.-W. Scientific Reports 2018, 8, (1), 13446.

57. Wardle, M. G.; Goss, J. P.; Briddon, P. R. Physical Review Letters 2006, 96, (20), 205504.

58. Bang, J.; Chang, K. J. Applied Physics Letters 2008, 92, (13), 132109.

59. Ip, K.; Overberg, M. E.; Heo, Y. W.; Norton, D. P.; Pearton, S. J.; Stutz, C. E.; Kucheyev, S. O.; Jagadish, C.; Williams, J. S.; Luo, B.; Ren, F.; Look, D. C.; Zavada, J. M. Solid-State Electronics 2003, 47, (12), 2255-2259. 